Research Article

\title{
Investigation of Load Sharing and Dynamic Load Characteristics of a Split Torque Transmission System with Double-Helical Gear Modification
}

\author{
Xuan Liu $\left(\mathbb{D},{ }^{1}\right.$ Zongde Fang $\left(\mathbb{D},{ }^{1}\right.$ Haitao Jia, ${ }^{2}$ Ning Zhao, ${ }^{1}$ Yunbo Shen, ${ }^{3}$ \\ Hui Guo, ${ }^{1}$ and Xijin Zhang ${ }^{1}{ }^{1}$ \\ ${ }^{1}$ School of Mechanical Engineering, Northwestern Polytechnical University, Xi'an 710072, China \\ ${ }^{2}$ No. 703 Research Institute of China Shipbuilding Industry Corporation, Harbin 150036, China \\ ${ }^{3}$ School of Mechatronic Engineering, Xi'an Technological University, Xi'an 710021, China \\ Correspondence should be addressed to Xuan Liu; zzgylx925@163.com
}

Received 16 March 2021; Revised 8 June 2021; Accepted 19 June 2021; Published 30 June 2021

Academic Editor: Paola Forte

Copyright (c) 2021 Xuan Liu et al. This is an open access article distributed under the Creative Commons Attribution License, which permits unrestricted use, distribution, and reproduction in any medium, provided the original work is properly cited.

\begin{abstract}
A new dynamic model for a two-input two-path split torque transmission system which considers meshing error, time-varying meshing stiffness, and meshing-in impact is proposed. Time-varying meshing stiffness and meshing-in impact of each gear pair are accurately calculated based on tooth contact analysis and loaded tooth contact analysis. Equivalent displacements of eccentricity error and installation error along the meshing line of second- and third-stages gears are derived. The modified tooth surface of a third-stage double-helical gear is obtained by optimizing the amplitude of static loaded transmission error and meshing-in impact via nondominated sorting genetic algorithm-II (NSGA-II). Influence of modification on load sharing and dynamic load characteristics of split torque transmission system is investigated. The results indicate that the system's dynamic meshing force increases when meshing-in impact is accounted for, which is unfavorable for the transmission. Following the modification of a double-helical gear, the dynamic load characteristics of the split torque transmission system are significantly improved, while its load sharing characteristics are improved to a certain extent.
\end{abstract}

\section{Introduction}

Representing a new and advanced configuration designed to replace the planetary transmission, the split torque transmission system (STTS) is increasingly employed in helicopter main reducer [1-5]. STTS is characterized by a driving pinion which simultaneously meshes with two gears, and each path only carries an equal half of the original load under ideal conditions. Due to the power closed-loop features of the STTS and the inevitable manufacturing and installation errors of the gears, a problem of uneven load distribution in each path of the STTS is inevitably caused. The unequal load sharing of the STTS increases the vibration and noise, while simultaneously affecting the STTS' reliability and durability.

Many research works have conducted numerous investigations on natural and load sharing characteristics of planetary and star transmission systems. Kahraman $[6,7]$ established a dynamic model of a planetary transmission. The author predicted natural modes of the system and investigated the influence of manufacturing and installation error on dynamic load coefficient of the system. Sondkar et al. [8] investigated the influence of double-helical (DH) gear stagger angle on dynamic response of a double-helical planetary gear system and found that the left and right sides of the DH gear can bear different dynamic load due to the effect of the stagger angle. Liu et al. [9] analyzed the influence of the profile error before and after the gear tooth separation on the vibration and dynamic meshing force of the herringbone planetary gears. Li et al. [10] established a model to predict the reliability of a helicopter planetary gear train under partial load and concluded that when the twin-engine helicopters are running on only one engine, the likelihood of 
teeth fatigue fracture is increased. Ren et al. [11] established a generalized dynamic model for a herringbone planetary gear train which considers the manufacturing eccentric errors of components and tooth profiles errors. Mo et al. [12, 13] investigated the influence mechanism of multicoupling errors, flexible support stiffness, and floating components on load sharing characteristics of a herringbone planetary transmission system. Mo et al. [14] proposed a new dynamic model for double-helical star gearing system and obtained the vibration model, natural characteristics, and dynamic response of the system. Wang et al. [15] established a dynamic model of a star herringbone gear transmission system and discovered that the system has four typical vibration modes. Wang et al. [16] investigated the influence of bearing's position and permutations on the load sharing performance of star gearing system. Bechhoefer et al. [17] processed the vibration signatures of a split torque gearbox through a number of gear analysis algorithms to quantify the gear fault performance. Gui et al. [18] analyzed the backlash influence on load sharing coefficient of the two-input cylindrical gear STTS. Dong et al. [19] established a dynamic model of the power-split transmission and obtained the frequency domain and time domain responses of the system. Zhao et al. [20] proposed a universal mathematical design method for a torque-split gear transmission and verified the correctness of the method through different types of gears. $\mathrm{Hu}$ et al. [21] established the gear-shaft-bearing dynamic model of two-path STTS and analyzed the influence of factors such as shaft angle and DH gear stagger angle on the system's dynamic characteristics and load sharing characteristics. Jin et al. [22] analyzed the influence of law and weight of backlash and center distance error on STTS load sharing characteristics.

Meshing error [11-14], time-varying meshing stiffness (TVMS) [23-26], and meshing-in impact [27-30] are important internal excitation of gear transmission system. Periodic TVMS excitation is the most obvious feature of gear system vibration that distinguished it from most mechanical systems. The finite element method and numerical analysis method are usually used to calculate TVMS. The former has high calculation accuracy but low calculation efficiency, while the latter has high calculation efficiency but low calculation accuracy. In this paper, the loaded tooth contact analysis (LTCA) method is used to calculate the TVMS of gear pair under static condition [31-33]. Gear modification has proven to be an effective method for reducing vibration and noise of the gear system. The modification is mainly carried out around the three elements of modification length, modification amount, and modification curve [34-37]. DH gear is generally used as the final-stage transmission in STTS because of its smooth transmission, compact structure, large carrying capacity, and self-balancing axial force. The final-stage transmission reduction ratio of approximately $10: 1$ to $14: 1$ can be achieved. Furthermore, transmission performance of the final-stage transmission has a crucial impact on the performance of the entire STTS. The existing research results show that the dynamic characteristics of a pair of $\mathrm{DH}$ gear transmission system can be significantly improved through the modification design of DH gear [38-40]. However, there are few studies on the influence of DH gear modification on load sharing and dynamic load characteristics of STTS.

In this paper, TVMS and meshing-in impact of each gear pair are calculated accurately via tooth contact analysis (TCA) and LTCA. Dynamic model of a two-input two-path STTS accounting for meshing error, TVMS, and meshing-in impact is established. The dynamic model can be employed to analyze the load sharing and dynamic load characteristics of STTS before and after modification under any working conditions. The influence of gear eccentricity and installation error on load sharing characteristics of the system is studied. By optimizing the amplitude of static loaded transmission error and meshing-in impact, the modification design of $\mathrm{DH}$ gear is carried out, and the topological modification tooth surface of the DH gear is constructed. Finally, the modification influence on load sharing and dynamic load characteristics of two-input two-path STTS is investigated. This research has important theoretical guidance and significance for the load sharing design of STTS and application of $\mathrm{DH}$ gear modification technology in helicopter main reducer.

\section{Internal Excitation Analysis of Two-Input Two-Path STTS}

2.1. Physical Model of Two-Input Two-Path STTS. Figure 1 shows the two-input two-path STTS for helicopter main reducer. The helicopter main reducer has two engines which transmit power to the input gear, one on the left and one on the right side. The input power on both sides is collected in the output gear, and the power is transmitted to the main rotor and tail stabilator through the rotor shaft. The two-input two-path STTS adopts three--stage transmission. The first stage adopts a spiral bevel gear pair to achieve the reversal of the transmission system. The second stage adopts a spur gear pair; i.e., one spur pinion simultaneously meshes with two large spur gears to achieve the power split. The third stage adopts a $\mathrm{DH}$ gear pair; i.e., two small $\mathrm{DH}$ pinions simultaneously mesh with one large $\mathrm{DH}$ gear to achieve power convergence. For the convenience of the following description, the gears of the two-input two-path STTS are numbered in sequence from 1 to 8 . The gears on the left and right sides of the first stage, second stage, and third stage are represented by $z_{i j}(i=L, R, j=1 \ldots 7)$. A large center output $\mathrm{DH}$ gear is designated as the gear number 8 , i.e., $z_{8}$.

As shown in Figure 2, coordinates of two-input two-path STTS are established. Generalized STTS coordinate system is $\mathrm{O}-\mathrm{XYZ}$, while the axis direction of gear 8 is defined as the $Z$ axis direction. Parameters $\sigma_{1}$ and $\sigma_{2}$ represent system installation angles, and $\psi$ represents the system layout angle. The angle between the center line of each gear pair and positive $X$-axis direction is indicated by $\gamma$ and the corresponding subscript, i.e., $\gamma_{L 34}$ and $\gamma_{R 34}$. The angle between the meshing line of each gear pair and the positive direction of the $X$-axis is denoted as $\eta$ and the corresponding subscript, i.e., $\eta_{L 34}$ and $\eta_{R 34}$. The angular displacement is taken 


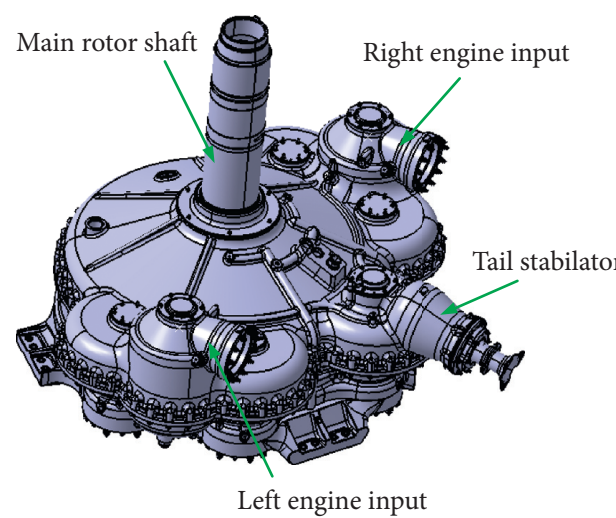

(a)

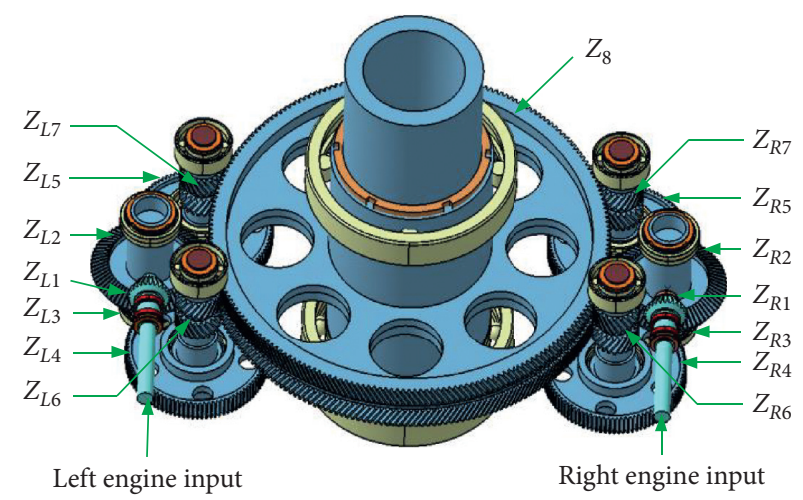

(b)

FIGURE 1: Two-input two-path STTS for helicopter main reducer: (a) helicopter main reducer; (b) 3D model of two-input two-path STTS.

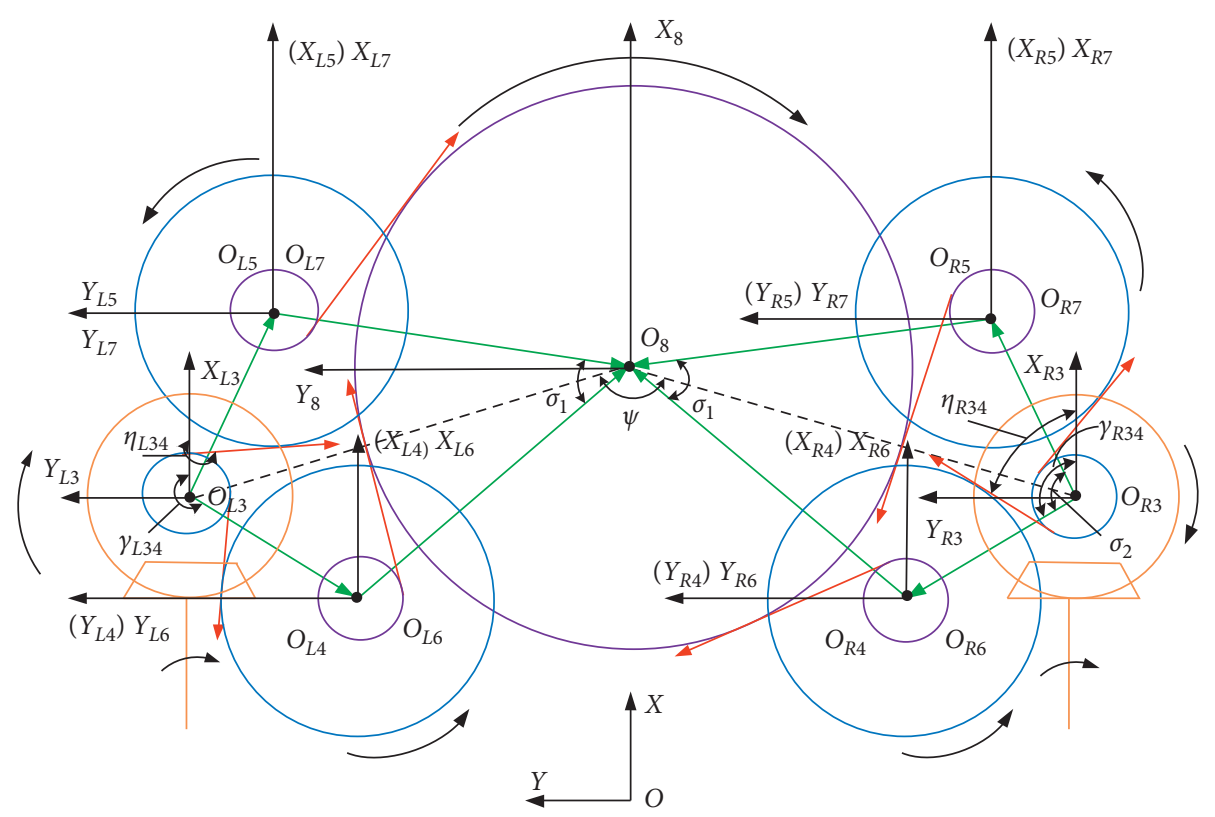

FIGURE 2: Coordinates of two-input two-path STTS.

counterclockwise from the positive $X$-axis as "+." The remaining angles are not marked in Figure 2, and the local coordinate systems of the first-stage gear pair are omitted.

\subsection{Meshing Error of Second-and Third-Stage Gears Analysis.} Since the load sharing of two-input two-path STTS is independent of the first-stage gear pair error, only equivalent displacement formula of the eccentricity and installation error along the meshing line of second- and third-stage gears is studied in this paper.

Second-stage spur gear pair (denoted as 34) of left-input two-path STTS is considered as an example. The projection relationship between the eccentricity error $E_{L 3}, E_{L 4}$ and installation error $A_{L 3}, A_{L 4}$ of spur pinion $z_{L 3}$ and the spur gear $z_{L 4}$, and the meshing line $M L_{L 34}$ is shown in Figure 3. Parameters $\lambda_{L 3}, \lambda_{L 4}$ and $\mu_{L 3}, \mu_{L 4}$ represent phase angles of the eccentricity and installation errors, respectively. The eccentricity and installation errors of the spur pinion $z_{L 3}$ and the spur gear $z_{L 4}$ are projected to the meshing line to obtain their respective equivalent meshing errors. Then, the equivalent meshing errors of two gears are combined to obtain the equivalent cumulative meshing error on the meshing line of gear pair 34 .

Therefore, the equivalent cumulative meshing error $e_{i 34}$ $(i=L, R)$ on the meshing line of the second-stage spur gear pair 34 can be expressed as

$$
\begin{aligned}
e_{i 34}(t)= & E_{i 3} \sin \left(-\omega_{i 3} t-\lambda_{i 3}+\gamma_{i 34}+\alpha_{t s}\right) \\
& +A_{i 3} \sin \left(-\mu_{i 3}+\gamma_{i 34}+\alpha_{t s}\right) \\
& +E_{i 4} \sin \left(-\omega_{i 4} t-\lambda_{i 4}+\gamma_{i 34}+\alpha_{t s}\right) \\
& +A_{i 4} \sin \left(-\mu_{i 4}+\gamma_{i 34}+\alpha_{t s}\right) .
\end{aligned}
$$


Similarly, the equivalent cumulative meshing error on the meshing line of the second-stage spur gear pair 35 and the third-stage DH gear pair 68 and 78 can be expressed as

$$
\begin{aligned}
e_{i 35}(t)= & E_{i 3} \sin \left(-\omega_{i 3} t-\lambda_{i 3}+\gamma_{i 35}+\alpha_{t s}\right) \\
& +A_{i 3} \sin \left(-\mu_{i 3}+\gamma_{i 35}+\alpha_{t s}\right) \\
& +E_{i 5} \sin \left(-\omega_{i 5} t-\lambda_{i 5}+\gamma_{i 35}+\alpha_{t s}\right) \\
& +A_{i 5} \sin \left(-\mu_{i 5}+\gamma_{i 35}+\alpha_{t s}\right), \\
e_{i 68}(t)= & -E_{i 6} \sin \left(-\omega_{i 6} t-\lambda_{i 6}+\gamma_{i 68}-\alpha_{t h}\right) \\
& -A_{i 6} \sin \left(-\mu_{i 6}+\gamma_{i 68}-\alpha_{t h}\right) \\
& -E_{8} \sin \left(-\omega_{8} t-\lambda_{8}+\gamma_{i 68}-\alpha_{t h}\right) \\
& -A_{8} \sin \left(-\mu_{8}+\gamma_{i 68}-\alpha_{t h}\right), \\
e_{i 78}(t)= & -E_{i 7} \sin \left(-\omega_{i 7} t-\lambda_{i 7}+\gamma_{i 78}-\alpha_{t h}\right) \\
& -A_{i 7} \sin \left(-\mu_{i 7}+\gamma_{i 78}-\alpha_{t h}\right) \\
& -E_{8} \sin \left(-\omega_{8} t-\lambda_{8}+\gamma_{i 78}-\alpha_{t h}\right) \\
& -A_{8} \sin \left(-\mu_{8}+\gamma_{i 78}-\alpha_{t h}\right) .
\end{aligned}
$$

where $\omega_{i 3}, \omega_{i 4}$, and $\omega_{i 5}$ are the angular velocities of spur gear $z_{i 3}, z_{i 4}$, and $z_{i 5}$, respectively. $\omega_{i 6}, \omega_{i 7}$, and $\omega_{8}$ are the angular velocities of DH gear $z_{i 6}, z_{i 7}$, and $z_{8}$. Parameters $\alpha_{\mathrm{ts}}$ and $\alpha_{t h}$ are the transverse pressure angle of spur gear and DH gear, respectively.

\subsection{Calculation of Time-Varying Meshing Stiffness of Gears.} The approach for LTCA model is used to solve the comprehensive meshing stiffness of gear pairs. The LTCA technology organically combines the geometric analysis and mechanical analysis of the gear. It has the following advantages [31]: (1) the whole tooth profile of large and small gear including tooth root transition surface is obtained by cutter tools generation, and the tooth profile is not simplified. At the same time, the flange structure is considered, and the finite element mesh is automatically generated by programming. The shape of the element is relatively regular, so the gear model itself has high accuracy. (2) The finite element method only needs one calculation to solve the nodal flexibility matrix of working tooth surface, while the normal flexibility matrix of contact line discrete points at different meshing positions in the meshing period can be obtained by reinterpolation. Compared with commercial finite element software, it takes less time and has higher efficiency. (3) It can reflect the micron-level (tooth modification) geometric feature changes of the tooth surface. (4) It can reflect the influence of the micron-level geometric features of the tooth surface on the mechanical properties (strength and vibration).

The finite element models of a driving gear for spiral bevel gear pair, spur gear pair, and DH gear pair are shown in Figure 4.

Taking DH gear as an example, the LTCA model of a DH gear is shown in Figure 5, and the LTCA models of a spiral bevel gear and a spur gear are detailed in $[32,33]$. The LTCA model is to simulate and analyze the gear pair under static conditions and then obtain the static transmission error

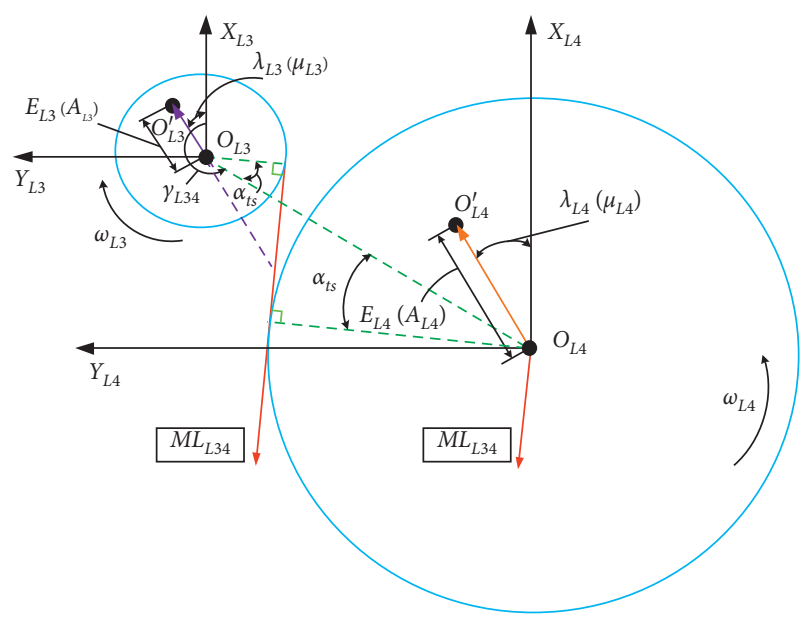

FIGURE 3: Diagram of eccentricity and assemble error of the spur gear pair 34 .

(STE) and static loaded transmission error (SLTE) of the gear pair. A mesh period of $\mathrm{DH}$ gear is divided into different mesh positions. Under the action of the total normal load $P$, the normal deformation $Z$ of different mesh positions can be obtained. The normal deformation $Z$ is actually the SLTE expressed by the linear displacement. Converting it into the form of angular displacement, it can be expressed as

$$
L_{T E}=3600 \times 180\left(\frac{Z}{\pi r_{b 2} \cos \beta_{b}}\right) .
$$

Here, $r_{b 2}$ and $\beta_{b}$ are the base cylinder radius and base helix angle of the $\mathrm{DH}$ gear, respectively.

Then, the amplitude of SLTE can be expressed as

$$
A_{\mathrm{LTE}}=\max \left(L_{\mathrm{TE}}\right)-\min \left(L_{\mathrm{TE}}\right) \text {. }
$$

Finally, the comprehensive meshing stiffness $k$ can be expressed as

$$
k(t)=\frac{F_{n}}{Z},
$$

where $F_{n}$ is normal force acting upon the tooth flank.

According to (3) (5), the SLTE and comprehensive meshing stiffness are two different description methods of the same nature of excitation. Thus, the two can be transformed into each other. Therefore, the fluctuation amplitude of the comprehensive meshing stiffness can be minimized by optimizing the amplitude of SLTE value in the subsequent optimization design.

The LTCA model can be used to accurately calculate the comprehensive meshing stiffness of each gear pair, and the time-varying meshing stiffness of each gear pair can be obtained by expressing it in the form of Fourier series, which can be directly introduced into dynamic equations of twoinput two-path STTS.

2.4. Calculation of Gear Meshing-In Impact. In the actual transmission process of gear pair, due to the manufacturing error, installation error, and elastic deformation of gear 


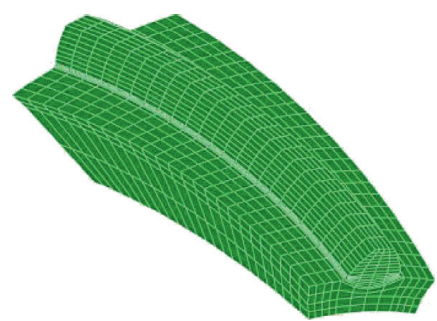

(a)

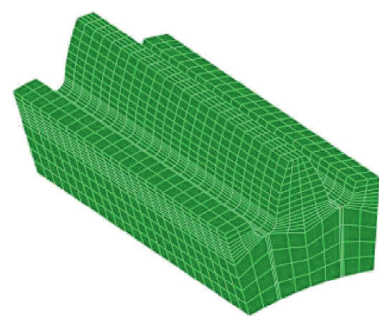

(b)

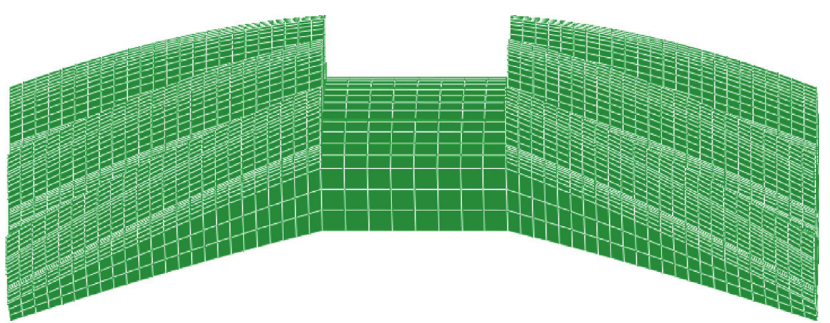

(c)

FIGURE 4: Finite element models of driving gear: (a) spiral bevel gear; (b) spur gear; (c) DH gear.

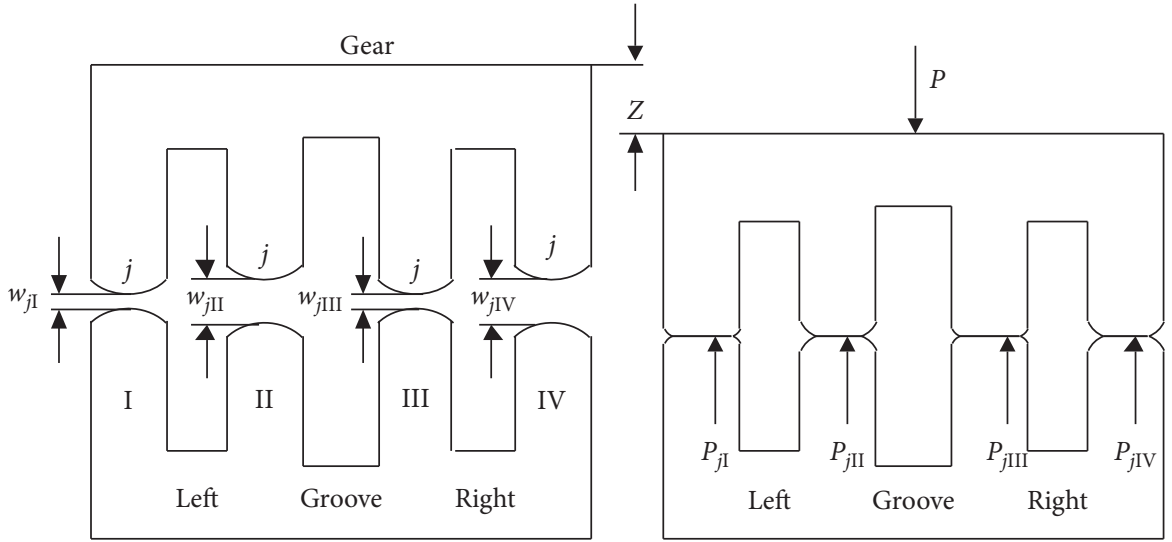

Pinion

FIgURE 5: The LTCA model for DH gear.

teeth, the normal pitches of the driving pinion $p_{b 1}$ and the driven gear $p_{b 2}$ along the line of action are no longer equal, resulting in a relative base pitch difference. The essence of meshing-in impact is that the tooth pair that enters meshingin advance produces a relative velocity difference along the meshing line at the meshing point. At this time, the position of the driven gear that is about to enter the mesh can be regarded as a slight angle of retraction based on the theoretical meshing position, which is defined as the reverse angle.

The key to calculate the meshing-in impact is to accurately obtain the position of the meshing point on the tooth surface. The two-input two-path STTS includes spiral bevel gear, spur gear, and double-helical gear. According to the geometric position relationship shown in Figure 6, for spur and $\mathrm{DH}$ gears with standard involute tooth surface, the reverse angle of the driven gear can be obtained by employing the reversal method. Then, the position of the meshing-in point of the standard tooth surface can be obtained [28]. In Figure 6, $\Delta \varphi_{\mathrm{kg}}$ is the reverse angle of the driven gear, and $\Delta \varphi_{k p}$ is the reverse angle of the driving pinion. Point $D$ is the actual meshing point, and the standard tooth surface contains meshing interference at this point. Point $E$ is the normal engagement point, and $E^{\prime}$ is the reversal point of the normal engagement point. $r_{p}$ and $r_{q}$ are pitch circle radii, and $r_{b p}$ and $r_{b g}$ are base circle radii of pinion and gear, respectively. $r_{a g}$ is the addendum circle radius of the gear.

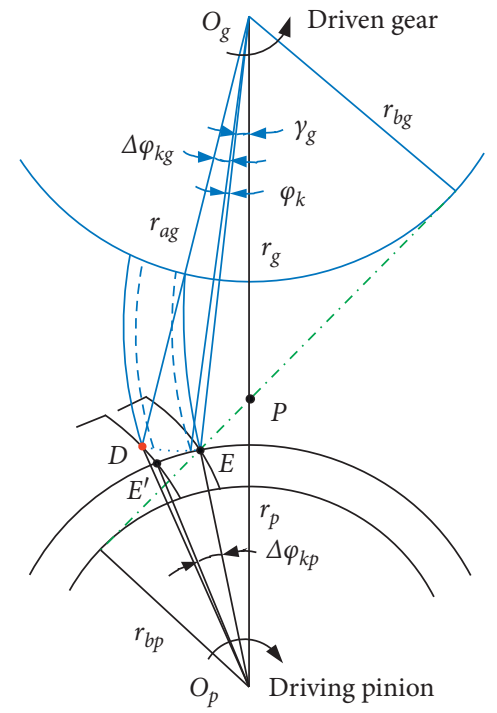

FIGURE 6: Schematic diagram of meshing-in impact of standard tooth surface.

The exact position of the initial meshing-in point of engagement, $D$, can be accurately determined as follows:

$$
r_{O_{p} D}=\sqrt{r_{a g}^{2}+\left(r_{p}+r_{g}\right)^{2}-2 r_{a g}\left(r_{p}+r_{g}\right) \cos \left(\gamma_{g}+\varphi_{k}+\Delta \varphi_{k g}\right)},
$$


where $\varphi_{k}=Z / r_{\mathrm{ag}}, \gamma_{\mathrm{g}}=\pi / 2-\alpha_{t}-\angle \mathrm{PEO}_{\mathrm{g}}$, and $\alpha_{\mathrm{t}}$ is the transverse pressure angle.

Due to the complex tooth surface, it is difficult to determine the position of the initial meshing point through geometric analysis methods for spiral bevel gear and modified DH gear. In this paper, the reversal angle of the above driven gear is calculated based on TCA and LTCA technology. Then, the initial meshing point position is determined. As shown in Figure 7, point A is the intersection of STE and SLTE curves, which represents the theoretical meshing point. $L_{\mathrm{TE} 2}$ is the SLTE value of the current meshing tooth pair (tooth pair 2) at the meshing point. $T_{\mathrm{E} 1}$ is the STE value of the previous meshing tooth pair (tooth pair 1) to the corresponding meshing point. Parameter $\Delta \varphi$ is the backward angle of the driven gear in theoretical engagement position, which can be expressed as

$$
\Delta \varphi=\left|L_{T E 2}-T_{E 1}\right| .
$$

The rotation angle of the driven gear at the actual meshing point can be expressed as

$$
\varphi_{2}^{*}=\varphi_{2}+\Delta \varphi,
$$

where $\varphi_{2}$ is the theoretical rotation angle of the driven gear at the engagement position.

By employing a new angle, $\varphi_{2}^{*}$, the TCA of the tooth surface is performed again. Then, the position vector and normal vector of actual meshing-in impact point on the tooth surface of the driving pinion and driven gear can be obtained.

Based on the position of the meshing point, the relative normal velocity $v_{s}$ of two teeth surfaces at the meshing point is calculated, which can be expressed as

$$
v_{s}=v_{n p}-v_{n g},
$$

where $v_{n p}$ and $v_{n g}$ are normal velocities of pinion and gear at the meshing point, respectively.

Then, the meshing-in impact of gear pair is calculated via impact mechanics method. The maximum meshing-in impact can be expressed as [29]

$$
F_{s}=\left(\frac{n+1}{2} \frac{J_{p} J_{g}}{\left(J_{p} r_{b_{g}}^{2}+J_{g} r_{b_{p}}^{2}\right)} v_{s}^{2} k_{s}^{1 / n}\right)^{n / n+1},
$$

where $J_{p}$ and $J_{g}$ are the moments of inertia of pinion and gear, respectively. $N$ is the deformation coefficient under the

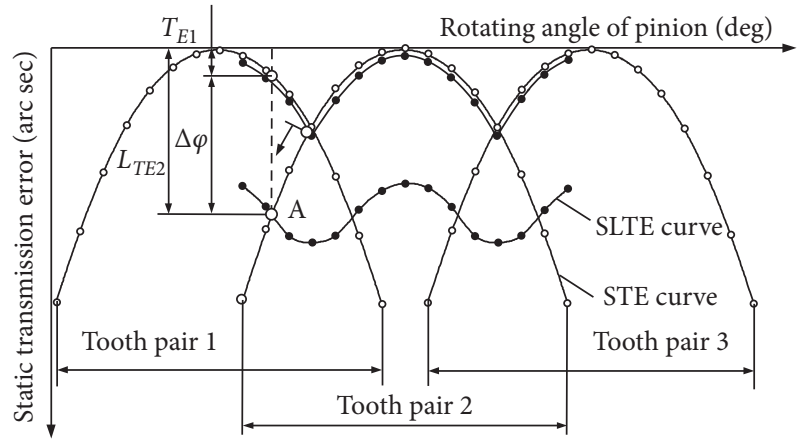

FIGURE 7: Analysis diagram of actual meshing point position of tooth surface.

static state, and $k_{s}$ is single meshing stiffness at the engagement point.

The meshing-in impact of each gear pair is expressed as the sum of Fourier series and can be directly introduced into dynamic equation of two-input two-path STTS.

\section{Dynamic Model of Two-Input Two-Path STTS}

Figure 8 shows the dynamic model of the two-input twopath STTS. In Figure 8, $m_{i j}$ and $I_{i j}$ are the mass and moment of inertia of each gear, respectively. $m_{8}$ and $I_{8}$ are the mass and moment of inertia of the central output gear $Z_{8} . T_{L 1}$ and $T_{R 1}$ are left- and right-input torques. $T_{\text {out }}$ is the output torque on the central output gear $Z_{8} . k_{i 12}, k_{i 34}, k_{i 35}, k_{i 68}$, and $k_{i 78}$ are the comprehensive meshing stiffness of each gear pair. $c_{i 12}, c_{i 34}, c_{i 35}, c_{i 68}$, and $c_{i 78}$ are the normal meshing damping of each gear pair. $k_{i t 23}, k_{i t 46}$, and $k_{i t 57}$ are the torsional stiffness of dual-gear shaft. $c_{i t 23}, c_{i t 46}$, and $c_{i t 57}$ are the torsional damping of dual-gear shaft. $\varphi_{\mathrm{ij}}$ represents torsional freedom of each gear about its $Z$-axis. $\varphi_{8}$ represents torsional freedom of central output gear $Z_{8}$ about its $Z$-axis. $k_{i x 1}, k_{i x 2}, k_{i x 4}$, and $k_{i x 5}$ denote the support stiffness of each gear in the $X$-direction. $c_{i x 1}, c_{i x 2}, c_{i x 4}$, and $c_{i \times 5}$ denote the support damping of each gear in the $X$-direction. $k_{i y 1}, k_{i y 2}$, $k_{i y 4}$, and $k_{i y 5}$ indicate the support stiffness of each gear in the $Y$-direction. $c_{i y 1}, c_{i y 2}, c_{i y 4}$, and $c_{i y 5}$ indicate the support damping of each gear in the $Y$-direction. The rest of support stiffness and support damping are not shown in the figure.

Dynamic model of two-input two-path STTS represents a vibration system with 49 degrees of freedom. Its generalized displacement matrix $\boldsymbol{X}$ can be expressed as

$$
X=\left\{\begin{array}{c}
x_{i 1}, y_{i 1}, z_{i 1}, \varphi_{i 1}, x_{i 2}, y_{i 2}, z_{i 2}, \varphi_{i 2}, x_{i 3}, y_{i 3}, \varphi_{i 3}, x_{i 4}, y_{i 4}, \varphi_{i 4}, x_{i 5}, y_{i 5}, \varphi_{i 5} \\
x_{i 6}, y_{i 6}, \varphi_{i 6}, x_{i 7}, y_{i 7}, \varphi_{i 7}, x_{8}, y_{8}, \varphi_{8}
\end{array}\right\},
$$




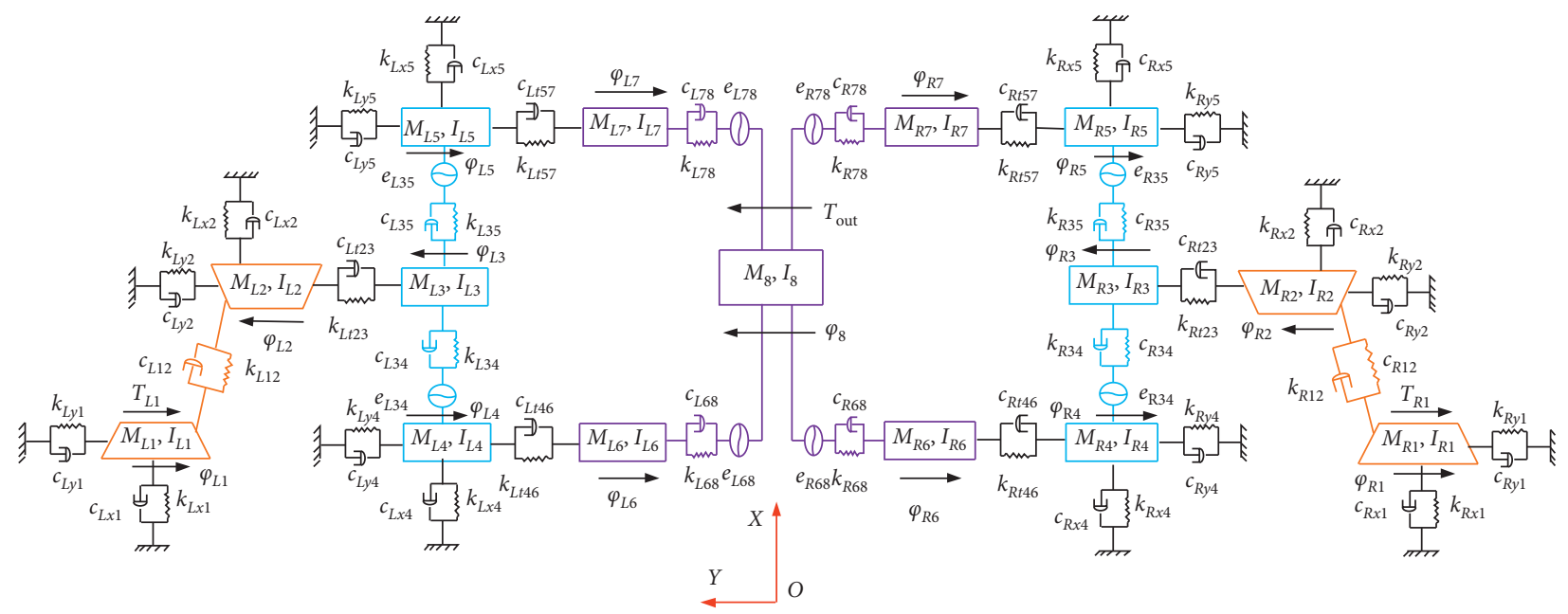

FIgURe 8: Dynamic model of two-input two-path STTS.

where $x, y$, and $z$ are the microdisplacements for two-input two-path STTS in each direction and $\varphi$ is the microrotation angle for two-input two-path STTS in Z-direction.
Normal relative displacement along the meshing line of each gear pair can be expressed as

$$
\left\{\begin{array}{l}
p_{i 12}(t)=a_{i x}\left(x_{i 1}-x_{i 2}\right)+a_{i y}\left(y_{i 1}-y_{i 2}\right)+a_{i z}\left(z_{i 1}-z_{i 2}\right)+P_{i y}\left(r_{i b 1} \varphi_{i 1}-r_{i b 2} \varphi_{i 2}\right) \\
p_{i 34}(t)=\left(x_{i 3}-x_{i 4}\right) \cos \zeta_{i 34}+\left(y_{i 3}-y_{i 4}\right) \sin \zeta_{i 34}+r_{i b 3} \varphi_{i 3}-r_{i b 4} \varphi_{i 4}-e_{i 34}(t) \\
p_{i 35}(t)=\left(x_{i 3}-x_{i 5}\right) \cos \zeta_{i 35}+\left(y_{i 3}-y_{i 5}\right) \sin \zeta_{i 35}+r_{i b 3} \varphi_{i 3}-r_{i b 5} \varphi_{i 5}-e_{i 35}(t) \\
p_{i 68}(t)=\left(\left(x_{i 6}-x_{8}\right) \cos \zeta_{i 68}+\left(y_{i 6}-y_{8}\right) \sin \zeta_{i 68}+r_{i b 6} \varphi_{i 6}-r_{b 8} \varphi_{8}-e_{i 68}(t)\right) \cos \beta_{b} \\
p_{i 78}(t)=\left(\left(x_{i 7}-x_{8}\right) \cos \zeta_{i 78}+\left(y_{i 7}-y_{8}\right) \sin \zeta_{i 78}+r_{i b 7} \varphi_{i 7}-r_{b 8} \varphi_{8}-e_{i 78}(t)\right) \cos \beta_{b}
\end{array}\right.
$$

where $p_{i 12}(t)$ is the equivalent meshing line displacement of first-stage spiral bevel gear pair, $p_{i 34}(t)$ and $p_{i 35}(t)$ are the equivalent meshing line displacement of second-stage spur gear pair, and $p_{i 68}(t)$ and $p_{i 78}(t)$ are the equivalent meshing line displacement of third-stage DH gear pair. Parameters $a_{i x}, a_{i y}$, and $a_{i z}$ are spiral bevel gear calculation coefficients.

The meshing force between the teeth of each gear pair can be expressed as

$$
\left\{\begin{array}{l}
F_{i n 12}=k_{i 12} \cdot p_{i 12}+c_{i 12} \cdot \dot{p}_{i 12}, \\
F_{i n 34}=k_{i 34} \cdot p_{i 34}+c_{i 34} \cdot \dot{p}_{i 34}, \\
F_{i n 35}=k_{i 35} \cdot p_{i 35}+c_{i 35} \cdot \dot{p}_{i 35}, \\
F_{i n 68}=k_{i 68} \cdot p_{i 68}+c_{i 68} \cdot \dot{p}_{i 68}, \\
F_{i n 78}=k_{i 78} \cdot p_{i 78}+c_{i 78} \cdot \dot{p}_{i 78} .
\end{array}\right.
$$


3.1. Dynamic Equations of First-Stage Spiral Bevel Gear. Dynamic equations for the left- and right-input first-stage spiral bevel gear can be expressed as

$$
\left\{\begin{array}{l}
m_{i 1} \ddot{x}_{i 1}+c_{i x 1} \dot{x}_{i 1}+k_{i x 1} x_{i 1}=-F_{i 12 x}, \\
m_{i 1} \ddot{y}_{i 1}+c_{i y 1} \dot{y}_{i 1}+k_{i y 1} y_{i 1}=-F_{i 12 y}, \\
m_{i 1} \ddot{z}_{i 1}+c_{i z 1} \dot{z}_{i 1}+k_{i z 1} z_{i 1}=-F_{i 12 z}, \\
I_{i 1} \ddot{\varphi}_{i 1}=T_{i 1}-F_{i n 12} r_{i b 1}-F_{i s 12} r_{i b 1}, \\
m_{i 2} \ddot{x}_{i 2}+c_{i x 2} \dot{x}_{i 2}+k_{i x 2} x_{i 2}=F_{i 12 x}, \\
m_{i 2} \ddot{y}_{i 2}+c_{i y 2} \dot{y}_{i 2}+k_{i y 2} y_{i 2}=F_{i 12 y} \\
m_{i 2} \ddot{z}_{i 2}+c_{i z 2} \dot{z}_{i 2}+k_{i z 2} z_{i 2}=F_{i 12 z} \\
I_{i 2} \ddot{\varphi}_{i 2}+c_{i t 23}\left(\dot{\varphi}_{i 2}-\dot{\varphi}_{i 3}\right)+k_{i t 23}\left(\varphi_{i 2}-\varphi_{i 3}\right)=F_{i n 12} r_{i b 2}+F_{i s 12} r_{i b 2},
\end{array}\right.
$$

where $T_{i 1}$ is the input torque of a spiral bevel gear, $F_{i s 12}$ is the meshing-in impact of spiral bevel gear, and $r_{i b 1}$ and $r_{i b 2}$ are the equivalent pitch radii of spiral bevel gear, respectively. Parameters $F_{i 12 x}=a_{i x}\left(F_{i n 12}+F_{i s 12}\right), F_{i 12 y}=a_{i y}\left(F_{i n 12}+F_{i s 12}\right)$, and $F_{i 12 z}=a_{i z}\left(F_{i n 12}+F_{i s 12}\right)$ are the component forces in each coordinate axis direction of a spiral bevel gear.

3.2. Dynamic Equations of Second-Stage Spur Gear. Dynamic equations for the left- and right-input secondstage spur gear can be expressed as

$$
\left\{\begin{array}{l}
m_{i 3} \ddot{x}_{i 3}+c_{i x 3} \dot{x}_{i 3}+k_{i x 3} x_{i 3}=-\left(F_{i n 34}+F_{i s 34}\right) \cos \zeta_{i 34}-\left(F_{i n 35}+F_{i s 35}\right) \cos \zeta_{i 34}, \\
m_{i 3} \ddot{y}_{i 3}+c_{i y 3} \dot{y}_{i 3}+k_{i y 3} y_{i 3}=-\left(F_{i n 34}+F_{i s 34}\right) \sin \zeta_{i 34}-\left(F_{i n 35}+F_{i s 35}\right) \sin \zeta_{i 34}, \\
I_{i 3} \ddot{\varphi}_{i 3}+c_{i t 23}\left(\dot{\varphi}_{i 3}-\dot{\varphi}_{i 2}\right)+k_{i t 23}\left(\varphi_{i 3}-\varphi_{i 2}\right)=-\left(F_{i n 34}+F_{i s 34}\right) r_{i b 3}-\left(F_{i n 35}+F_{i s 35}\right) r_{i b 3}, \\
m_{i 4} \ddot{x}_{i 4}+c_{i x 4} \dot{x}_{i 4}+k_{i x 4} x_{i 4}=\left(F_{i n 34}+F_{i s 34}\right) \cos \zeta_{i 34}, \\
m_{i 4} \ddot{y}_{i 4}+c_{i y 4} \dot{y}_{i 4}+k_{i y 4} y_{i 4}=\left(F_{i n 34}+F_{i s 34}\right) \sin \zeta_{i 34}, \\
I_{i 4} \ddot{\varphi}_{i 4}+c_{i t 46}\left(\dot{\varphi}_{i 4}-\dot{\varphi}_{i 6}\right)+k_{i t 46}\left(\varphi_{i 4}-\varphi_{6}\right)=\left(F_{i n 34}+F_{i s 34}\right) r_{i b 4}, \\
m_{i 5} \ddot{x}_{i 5}+c_{i x 5} \dot{x}_{i 5}+k_{i x 5} x_{i 5}=\left(F_{i n 35}+F_{i s 35}\right) \cos \zeta_{i 35}, \\
m_{i 5} \ddot{y}_{i 5}+c_{i y 5} \dot{y}_{i 5}+k_{i y 5} y_{i 5}=\left(F_{i n 35}+F_{i s 35}\right) \sin \zeta_{i 35}, \\
I_{i 5} \ddot{\varphi}_{i 5}+c_{i t 57}\left(\dot{\varphi}_{i 5}-\dot{\varphi}_{i 7}\right)+k_{i t 57}\left(\varphi_{i 5}-\varphi_{i 7}\right)=\left(F_{i n 35}+F_{i s 35}\right) r_{i b 5}
\end{array}\right.
$$

where $r_{i b 3}, r_{i b 4}$, and $r_{i b 5}$ are the base circle radii of secondstage spur gear, respectively. $F_{i s 34}$ and $F_{i s 35}$ are the meshingin impact of spur gear pair.
3.3. Dynamic Equations of Third-Stage DH Gear. Dynamic equations for the left- and right-input third-stage $\mathrm{DH}$ gear can be expressed as

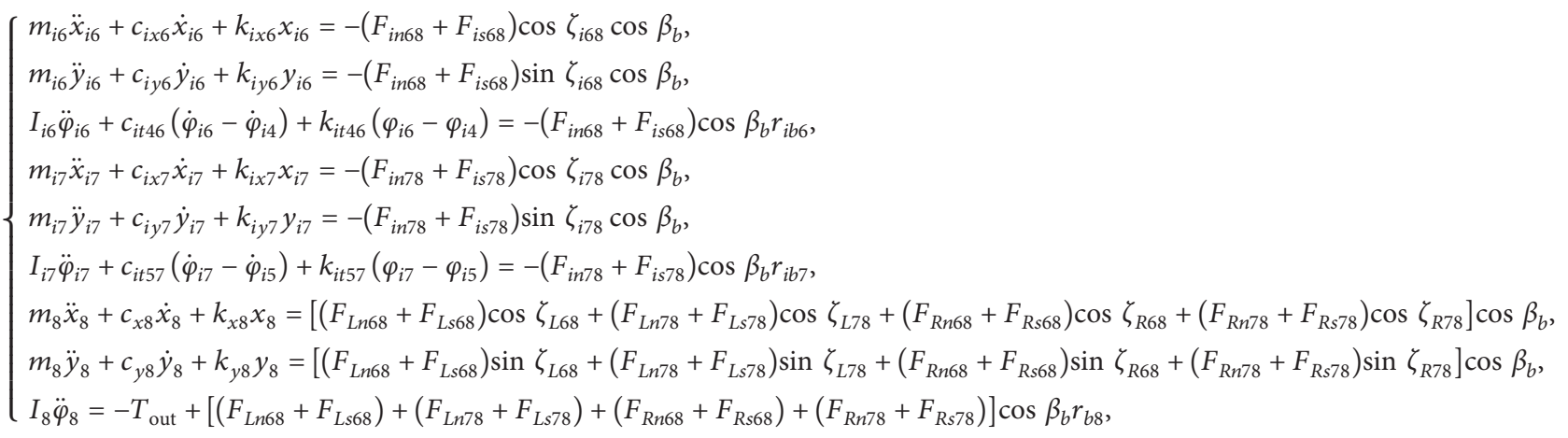

where $r_{i b 6}, r_{i b 7}$, and $r_{b 8}$ are the base circle radii of $\mathrm{DH}$ gear, respectively. $T_{\text {out }}$ is the output torque, while $F_{i s 68}$ and $F_{i s 78}$ are the meshing-in impact of $\mathrm{DH}$ gear pair, respectively.
3.4. Calculation of the Load Sharing Coefficient. The essence of load sharing coefficient (LSC) is to characterize the difference of power split in the two-path STTS, that is, the 
difference in the transmission load of each gear caused by various factors (manufacturing error, installation error, and vibration). A Runge-Kutta method is used to solve the dynamic equations of the system. It should be noted that in the process of using coordinate transformation to eliminate the rigid body displacement of the system, for the two-input two-path STTS, there is a rigid body displacement in the left engine closed-loop system and the right engine closed-loop system, which need to be eliminated together. Finally, a dynamic model with 48 degrees of freedom can be obtained.

The instantaneous LSC in each tooth frequency cycle of each path of the left- and right-input second stage and third stage is defined as follows:

$$
\left\{\begin{array}{l}
\operatorname{LSC}_{i 34}=\frac{2\left(F_{i d 34_{k 1}}\right)_{\max }}{\left(F_{i d 34_{k 1}}\right)_{\max }+\left(F_{i d 35_{k 1}}\right)_{\max }}, \\
\mathrm{LSC}_{i 35}=\frac{2\left(F_{i d 35_{k 1}}\right)_{\max }}{\left(F_{i d 34_{k 1}}\right)_{\max }+\left(F_{i d 35_{k 1}}\right)_{\max }}, \\
\mathrm{LSC}_{i 68}=\frac{2\left(F_{i d 68_{k 2}}\right)_{\max }}{\left(F_{i d 68_{k 2}}\right)_{\max }+\left(F_{i d 78_{k 2}}\right)_{\max }}, \\
\mathrm{LSC}_{i 78}=\frac{2\left(F_{i d 78_{k 2}}\right)_{\max }}{\left(F_{i d 68_{k 2}}\right)_{\max }+\left(F_{i d 78_{k 2}}\right)_{\max }},
\end{array}\right.
$$

where $k_{1}=1, \ldots, m_{1}$ and $k_{2}=1, \ldots, m_{2}$. Parameters $m_{1}$ and $m_{2}$ are meshing gear frequency cycles of second stage and third stage within the system period, respectively. $\left(F_{i d 34_{k 1}}\right)_{\max }$ and $\left(F_{i d 35_{k 1}}\right)_{\max }$ are maximum meshing forces in the $k_{1}$ tooth frequency cycle of the second stage, while $\left(F_{i d 68_{k}}\right)_{\max }$ and $\left(F_{i d 78_{k}}\right)_{\max }$ are the maximum meshing forces in the $k_{2}$ tooth frequency cycle of the third stage.

The LSC of the system period of the left- and right-input second stage and third stage is defined as follows:

$$
\left\{\begin{array}{l}
\mathrm{LSC}_{i s t s}=\max \left(\mathrm{LSC}_{i 34}, \mathrm{LSC}_{i 35}\right), \\
\mathrm{LSC}_{i c t s}=\max \left(\mathrm{LSC}_{i 68}, \mathrm{LSC}_{i 78}\right) .
\end{array}\right.
$$

Therefore, the LSC of the left- and right-input two-path STTS can be expressed as

$$
\mathrm{LSC}_{i}=\max \left(\mathrm{LSC}_{i s t s}, \mathrm{LSC}_{i c t s}\right) \text {. }
$$

\section{DH Gear Modification Optimization Design}

Topological modification includes tooth profile modification and longitudinal modification, both of which are composed of two quadratic parabolas and a straight line, as shown in Figure 9. Parameters $y_{1}$ and $y_{3}$ are the maximum modification amount and modification length of the tooth root, respectively. Parameters $y_{2}$ and $y_{4}$ are the maximum modification amount and modification length of the tooth top, respectively. $y_{5}$ is the maximum modification amount at both tooth ends. $y_{6}$ is the length of the nonmodification area in the tooth direction. $H$ and $L$ are the effective tooth height and tooth length, respectively. $s_{1}, s_{2}, s_{3}$, and $s_{4}$ are the location coordinates of the modification points. For topological modification of DH gear (driving gear), left and right helical gear modification methods are the same.

Topological modification curve has to be defined prior to TCA simulation. The general form of the modification curve is as follows:

$$
\xi= \begin{cases}C_{a}\left(\frac{s-s_{2}}{s_{1}-s_{2}}\right)^{c}, & s_{1} \leq s \leq s_{2}, \\ 0, & s_{2}<s<s_{3}, \\ C_{q}\left(\frac{s-s_{3}}{s_{4}-s_{3}}\right)^{c}, & s_{3} \leq s \leq s_{4},\end{cases}
$$

where $\xi$ is the modification amount, $s$ is the modification point coordinate, $s \in\left[s_{1}, s_{4}\right], C_{a}$ and $C_{q}$ are modification values, and $c$ is the index of the modification curve.

According to the modification curve, the grid node modification value $\xi$ is calculated. Then, smooth modification amount surface is obtained by fitting the node data through the cubic B-spline. The relationship between the rotating projection surface and the theoretical tooth surface is as follows:

$$
\left\{\begin{array}{l}
u=\sqrt{r_{1 u}^{2}+r_{1 v}^{2}} \\
v=r_{1 w}
\end{array}\right.
$$

where $r_{1 u}, r_{1 v}$, and $r_{1 w}$ are the coordinate components of $\mathrm{DH}$ pinion theoretical tooth surface position vector.

The modified tooth surface is constructed by superimposing the theoretical tooth surface and the modification amount surface. Its position vector and normal vector can be expressed as

$$
\left\{\begin{array}{l}
R_{1}\left(u_{1}, l_{1}\right)=r_{1}\left(u_{1}, l_{1}\right)+\xi(u, v) n_{1}\left(u_{1}, l_{1}\right) \\
N_{1}\left(u_{1}, l_{1}\right)=\left(\frac{\partial r_{1}}{\partial u_{1}}+\frac{\partial \xi}{\partial u_{1}} n_{1}+\frac{\partial n_{1}}{\partial u_{1}} \xi\right) \times\left(\frac{\partial r_{1}}{\partial l_{1}}+\frac{\partial \xi}{\partial l_{1}} n_{1}+\frac{\partial n_{1}}{\partial l_{1}} \xi\right)
\end{array}\right.
$$

where $u_{1}$ and $l_{1}$ are the tooth surface parameters, and $r_{1}\left(u_{1}\right.$, $\left.l_{1}\right)$ and $n_{1}\left(u_{1}, l_{1}\right)$ are the position and normal vectors of the $\mathrm{DH}$ pinion theoretical tooth surface, respectively.

The amplitude of SLTE and meshing-in impact are the main factors affecting the vibration and noise of the $\mathrm{DH}$ gear. In this paper, the optimization objective is to minimize the synthesis of the two. Parameters $\left(y_{1}, y_{2}, y_{3}, y_{4}, y_{5}\right.$, and $\left.y_{6}\right)$ 


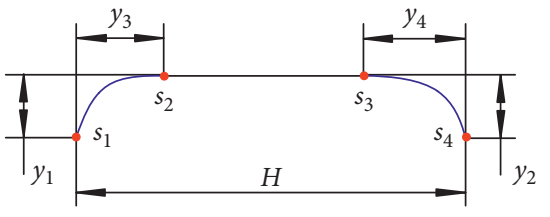

(a)

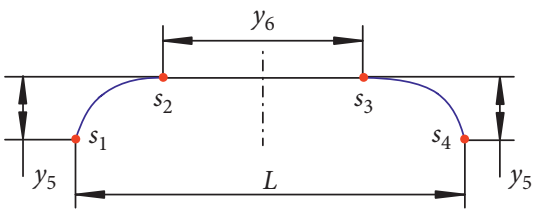

(b)

FIgURE 9: Topological modification design of DH gear: (a) profile modification; (b) longitudinal modification.

are employed for optimization. Modification optimization design model is represented as follows:

$$
\left\{\begin{array}{l}
F_{1}\left(y_{1}, y_{2}, y_{3}, y_{4}, y_{5}, y_{6}\right)=\min \left(\frac{f_{1}}{f_{10}}\right), \\
F_{2}\left(y_{1}, y_{2}, y_{3}, y_{4}, y_{5}, y_{6}\right)=\min \left(\frac{f_{2}}{f_{20}}\right), \\
\text { S.t } \quad q_{\min } \leq y_{1}, y_{2}, y_{5} \leq q_{\max }, \\
h_{\min } \leq y_{3}, y_{4} \leq h_{\max }, \\
l_{\min } \leq y_{6} \leq l_{\max },
\end{array}\right.
$$

where $f_{10}$ and $f_{20}$ are the amplitude of SLTE and meshing-in impact, respectively, of a nonmodified DH gear. $f_{1}$ and $f_{2}$ are the amplitude of SLTE and meshing-in impact, respectively, of a modified DH gear. Parameters $q_{\min }$ and $q_{\max }$ represent the lower and the upper bound, respectively, for $y_{1}, y_{2}$, and $y_{5} . h_{\min }$ and $h_{\max }$ are the lower and the upper bound, respectively, for $y_{3}$ and $y_{4} \cdot l_{\min }$ and $l_{\max }$ represent the lower and the upper bound, respectively, for $y_{6}$.

NSGA-II employs fast nondominated sorting algorithm and a crowded distance comparison operator while introducing an elite strategy, which has low computational complexity and high computational efficiency. Hence, it is used in this paper to solve the aforementioned optimization model. The flowchart of topological modification optimization of DH gear is shown in Figure 10.

\section{Numerical Analysis}

Some specific parameters of two-input two-path STTS are shown in Table 1.

TVMS and meshing-in impact of first-stage spiral bevel gear are shown in Figure 11. The maximum meshing-in impact is equal to $4080.284 \mathrm{~N}$.

TVMS and meshing-in impact of second-stage spur gear are shown in Figure 12. The maximum meshing-in impact is equal to $8046.040 \mathrm{~N}$.

Optimized DH pinion topological modification tooth surface is shown in Figure 13. The optimized modification parameters are $y_{1}=0.023 \mathrm{~mm}, y_{2}=0.035 \mathrm{~mm}, y_{3}=2.30 \mathrm{~mm}$, $y_{4}=2.01 \mathrm{~mm}, y_{5}=0.013 \mathrm{~mm}$, and $y_{6}=8.19 \mathrm{~mm}$.

TVMS and meshing-in impact of third-stage DH gear before and after modification are shown in Figure 14. The

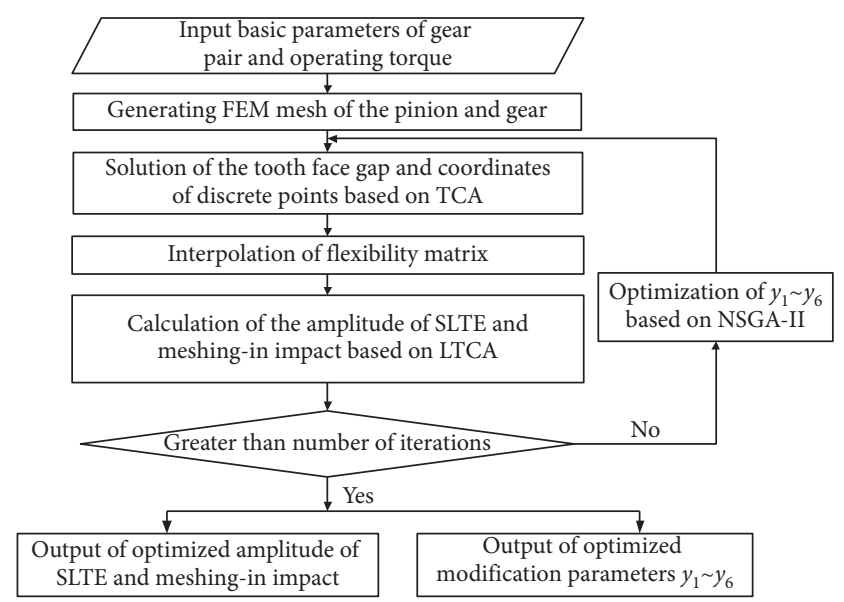

FIGURE 10: Flowchart for optimization of DH gear topological modification.

TABLE 1: Gear parameters of two-input two-path STTS.

\begin{tabular}{lccc}
\hline Name & $\begin{array}{c}\text { Spiral bevel } \\
\text { gear }\end{array}$ & $\begin{array}{c}\text { Spur } \\
\text { gear }\end{array}$ & $\begin{array}{c}\text { DH } \\
\text { gear }\end{array}$ \\
\hline $\begin{array}{l}\text { Teeth number (pinion, } \\
\text { gear) }\end{array}$ & 27,74 & 34,107 & 23,215 \\
Module (mm) & 3.85 & 3.5 & 3.965 \\
Tooth width (mm) & 45.5 & 52 & 50 \\
Pressure angle (deg) & 20 & 22.5 & 20 \\
Helix angle (deg) & 30 & 0 & 30 \\
Shaft angle (deg) & 87 & - & - \\
Input power (KW) & 950 & 950 & 475 \\
Input speed (r/min) & 20900 & 7626 & 2423 \\
Installation angle $\sigma_{1}, \sigma_{2}$ & \multicolumn{4}{c}{$42.165,105.157$} \\
(deg) & \multicolumn{4}{c}{150} \\
Layout angle $\psi(\mathrm{deg})$ &
\end{tabular}

maximum meshing-in impact is equal to $3909.481 \mathrm{~N}$ before modification and $1084.720 \mathrm{~N}$ after modification. The meshing-in impact is reduced by $72.25 \%$ after modification. In Figure 14 and the following figures, "non-mod" represents the results of a DH pinion tooth surface with nonmodification, while "mod" represents the results of a $\mathrm{DH}$ pinion tooth surface with the topological modification.

5.1. Dynamic Analysis of Two-Input Two-Path STTS. In twoinput two-path STTS, the meshing period of the first-stage gear pair is the shortest, while that of the third-stage gear pair is the longest. In order to consider the influence of meshing-in impact of all gear pair levels, the following 


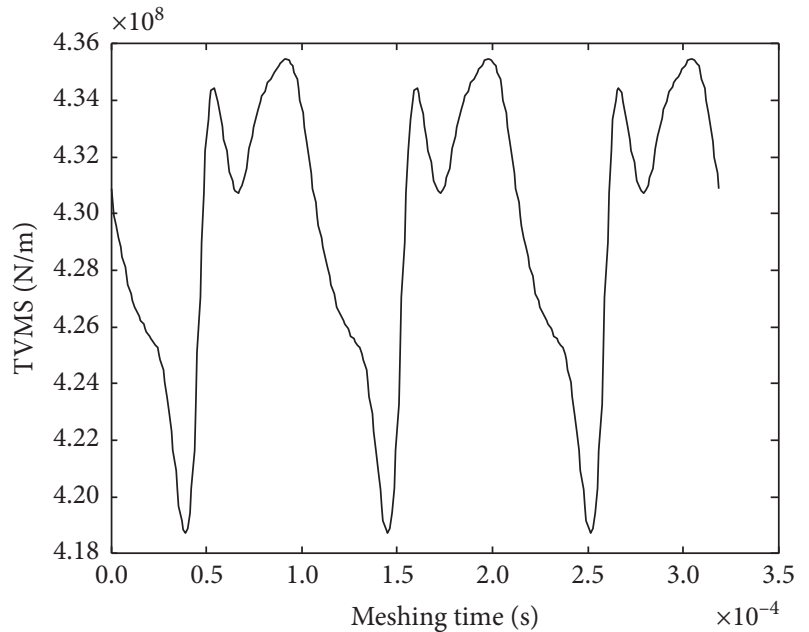

(a)

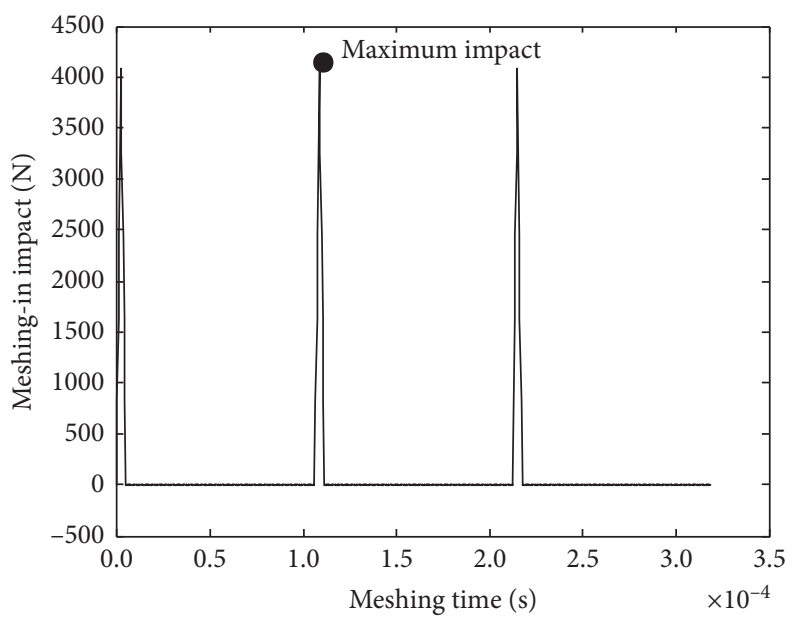

(b)

FIgURE 11: Inter-excitation of spiral bevel gear: (a) TVMS; (b) meshing-in impact.

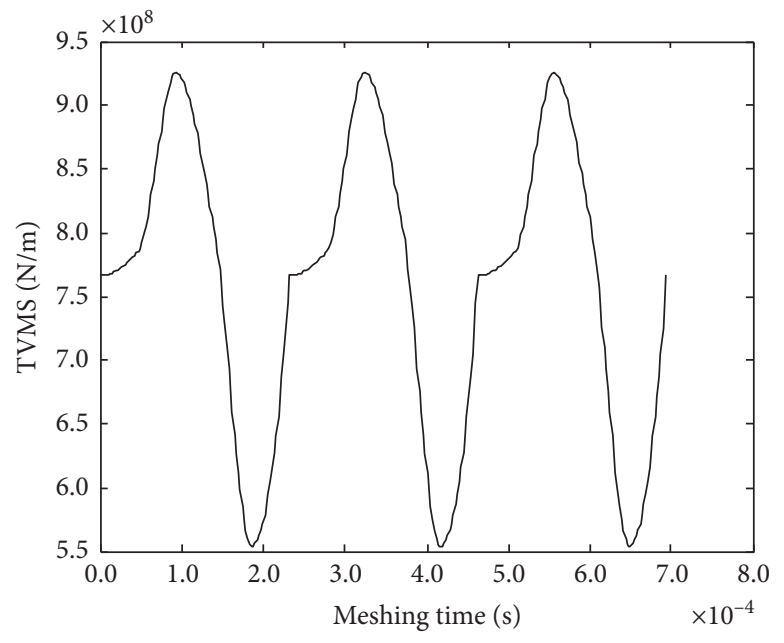

(a)

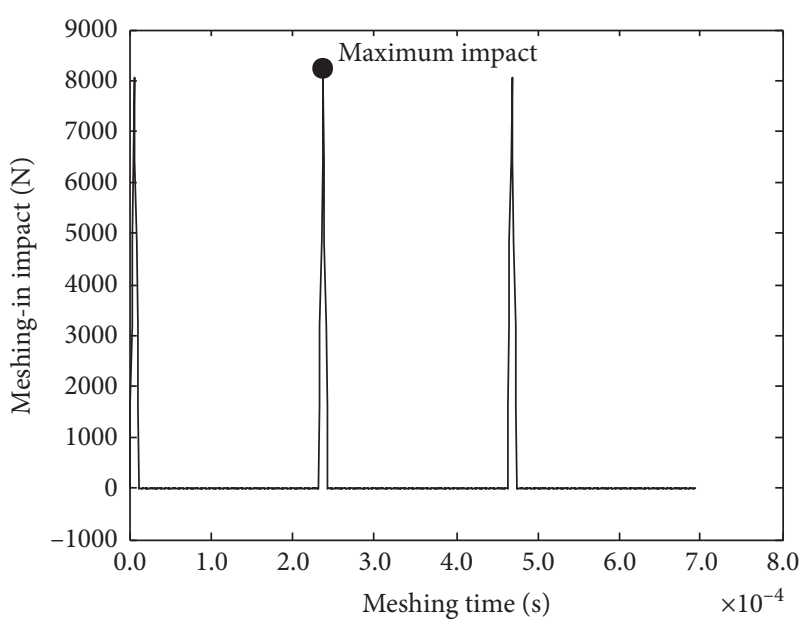

(b)

FIgURE 12: Inter-excitation of spur gear: (a) TVMS; (b) meshing-in impact.

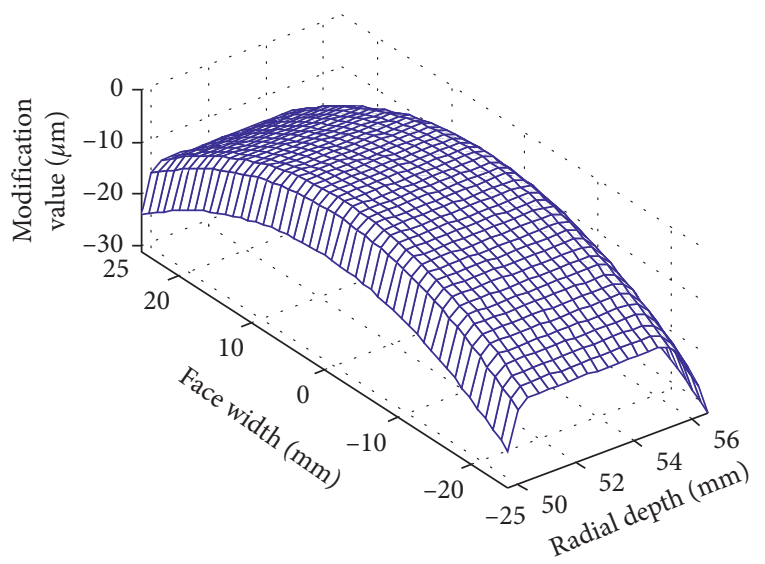

FIgURE 13: Topological modification of DH pinion tooth surface. simulation calculation uses $1 / 100$ of the meshing period of the first-stage gear pair as the step length. The simulation result employs the calculation results of the last 1500 meshing periods of the third-stage gear pair.

When the DH pinion is not modified, the influence of the installation error and eccentricity error of the secondstage spur gear and third-stage $\mathrm{DH}$ gear on the left-input two-path STTS LSC is shown in Figure 15. The law of the right-input two-path STTS LSC is similar to the law of the left-input two-path STTS. When a certain error emerges, the remaining errors are nullified and remain unaltered.

According to Figure 15, the LSC of the left-input twopath STTS linearly increases with an increase of the installation error (eccentricity error). In other words, the greater the installation error (eccentricity error), the greater the system's LSC, and the worse the load sharing 


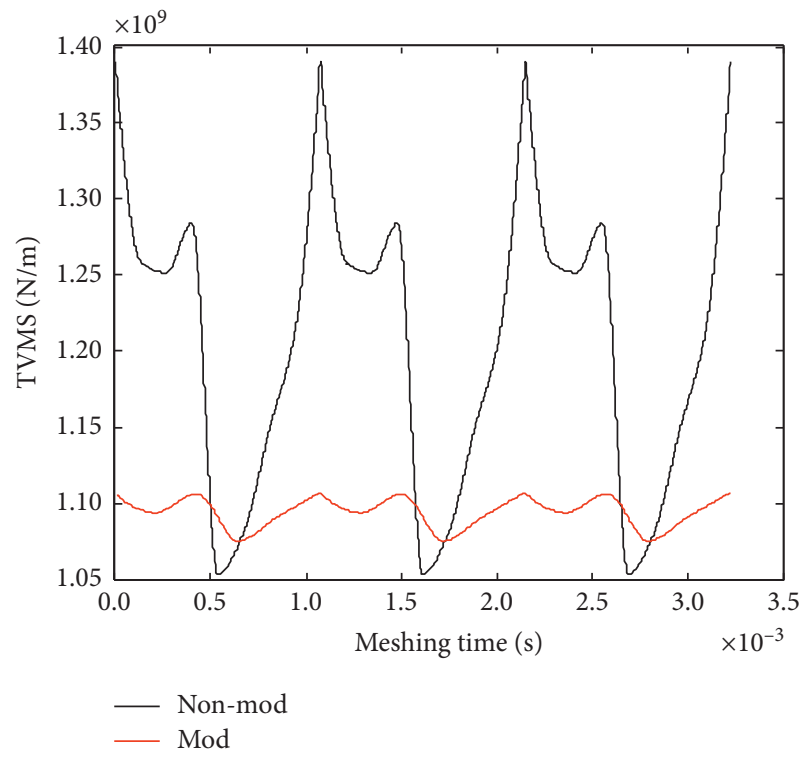

(a)

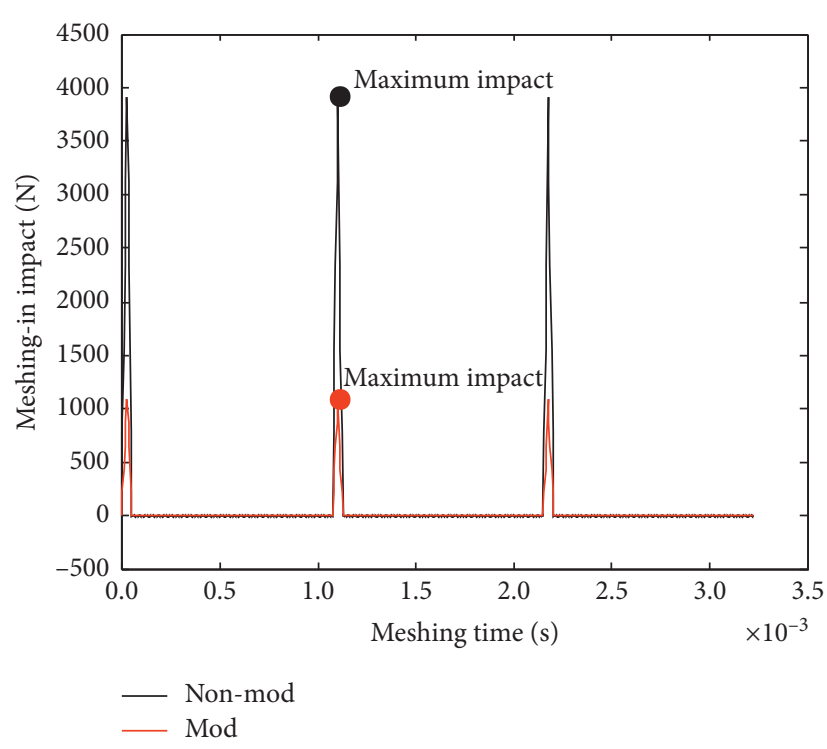

(b)

FIgURE 14: Interexcitation of DH gear before and after modification: (a) TVMS; (b) meshing-in impact.

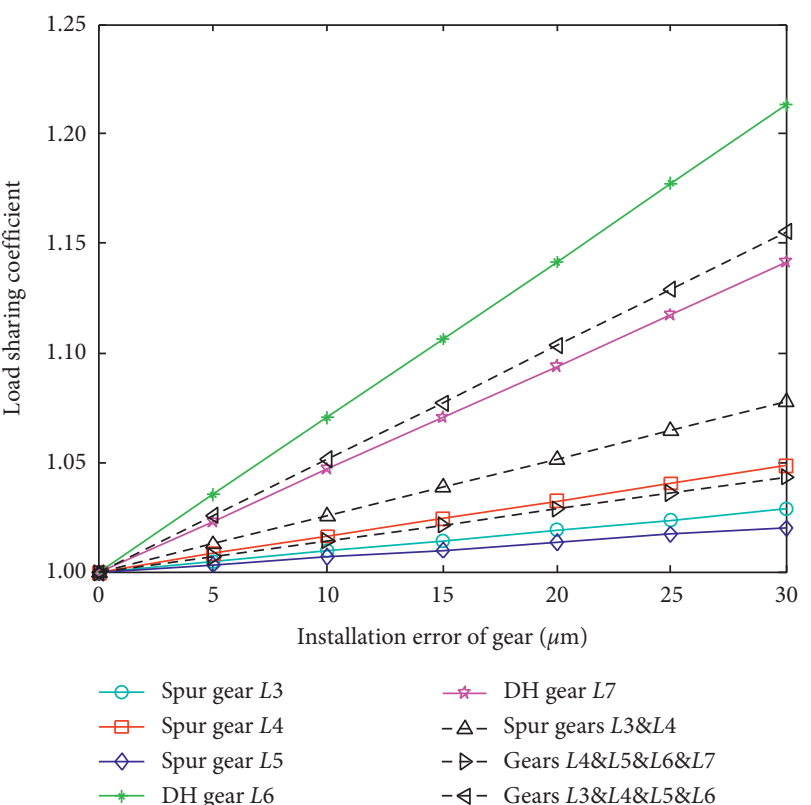

(a)

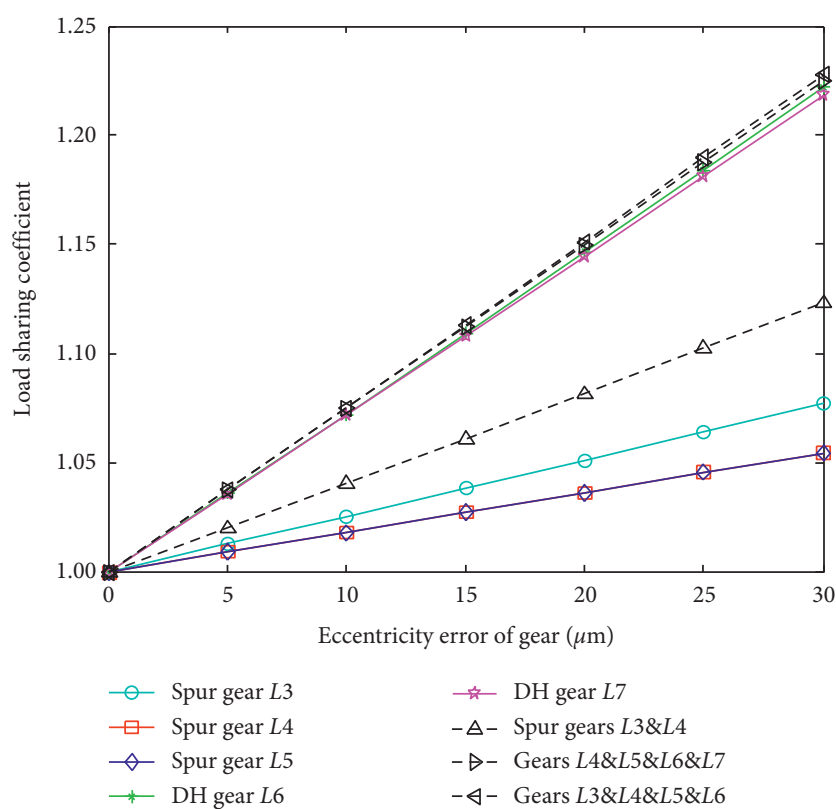

(b)

FIGURE 15: The variation law of LSC of left-input two-path STTS: (a) the influence of installation error; (b) the influence of eccentricity error.

performance. The influence of third-stage DH gears installation error (eccentricity error) on LSC is greater than that of the second-stage spur gears. Under the action of gear comprehensive installation error, LSC may be less than or greater than that of gear installation error alone. However, under the action of gear comprehensive eccentricity error, LSC must be greater than that under the action of the gear eccentricity error alone. To summarize, the influence of the eccentricity error on STTS load sharing performance is greater than that of the installation error. In gear design, the eccentricity error of the third-stage DH gears must be strictly controlled.

In the subsequent analysis, errors of second and thirdstage gears are selected according to the gear accuracy grade of 5 , as shown in Table 2 [41].

Dynamic meshing force of first-stage gear pair of the leftinput two-path STTS with and without considering meshing-in impact is shown in Figure 16. Dynamic force of the 
TABLE 2: Comprehensive error of left-input two-path STTS.

\begin{tabular}{lcc}
\hline Part name & Eccentricity error $(\mathrm{mm})$ & Installation error $(\mathrm{mm})$ \\
\hline Spur gear $Z_{L 3}$ & 0.008 & 0.008 \\
Spur gear $Z_{L 4}, Z_{L 5}$ & 0.012 & 0.012 \\
Double-helical gear $Z_{L 6}, Z_{L 7}$ & 0.008 & 0.008 \\
\hline
\end{tabular}

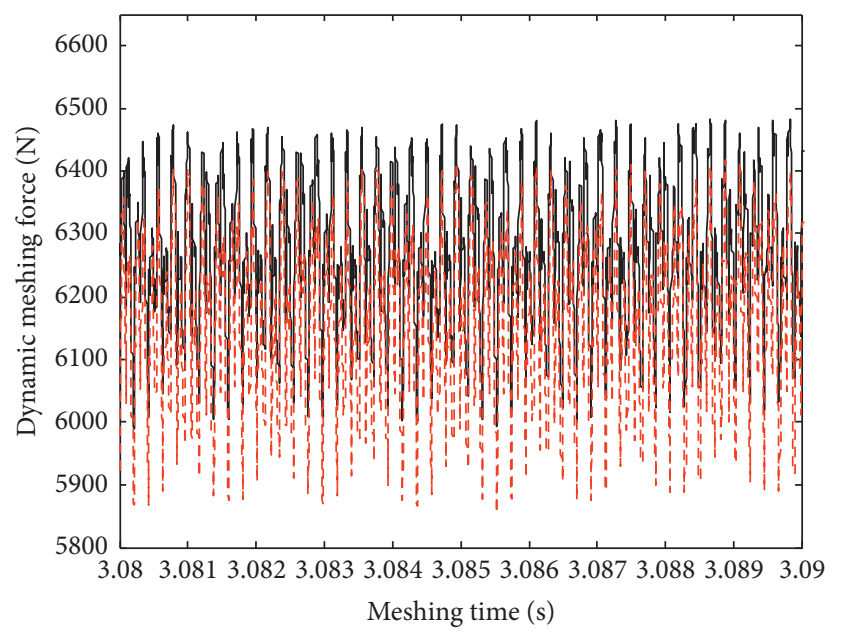

_ $F_{L d 12}$ non-mod with considering meshing-in impact

- - $F_{L d 12}$ non-mod without considering meshing-in impact

Figure 16: The dynamic meshing force of first-stage gear pair on the meshing line.

first-stage gear pair slightly increases when meshing-in impact is accounted for. Since this paper only analyzes the load sharing and dynamic load of the second and third-stage gear pairs of the system, the dynamic characteristics of the first-stage gear pair are not discussed too much.

The maximum meshing force in the tooth frequency cycle of a second and third-stage gear pair of the left-input two-path STTS with and without considering meshing-in impact is shown in Figure 17.

According to the ISO standard for gears, the dynamic load factor is defined as the ratio of dynamic load to the static load. The dynamic load factor of the second-stage spur gear pair of the STTS is increased from 1.41596 without considering meshing-in impact to 1.42443 with considering meshing-in impact, and the dynamic load performance is reduced by $2.00 \%$. The dynamic load factor of the third-stage DH gear pair of the STTS is increased from 1.20645 without considering meshing-in impact to 1.20669 with considering meshing-in impact, and the dynamic load performance is reduced by $0.12 \%$.

The instantaneous LSC of the second-stage spur gear pair and third-stage DH gear pair with and without the consideration of meshing-in impact is shown in Figure 18. According to the LSC definition, its value cannot be lower than 1 . In other words, the average system load without error is the load that the path transmission must bear. The LSC of the second-stage spur gear pair decreases from 1.06387 without considering meshing-in impact to 1.06332 with considering meshing-in impact, thus increasing the load sharing performance by $0.86 \%$. The LSC of the third-stage
DH gear pair decreases from 1.09669 without considering meshing-in impact to 1.09603 with considering meshing-in impact, thereby increasing the load sharing performance by $0.68 \%$. The LSC of the left-input two-path STTS depends on the LSC of the third-stage, which is equal to $L S C_{L}=1.09603$ with consideration of meshing-in impact. When accounting for meshing-in impact, although the dynamic meshing force of the system increases, the increase of denominator in (17) is larger than that of the numerator, which ultimately leads to a slight decrease in the LSC of the STTS. It should be noted that if the increase of the numerator in (17) is greater than the increase of the denominator after the meshing-in impact is considered, the LSC of the system will increase. However, after considering the meshing-in impact, the dynamic meshing force of the system will inevitably increase, and the dynamic load characteristics will inevitably decrease, which is unfavorable to the transmission characteristics of the entire system.

\subsection{Influence of Modification on Load Sharing and Dynamic} Load Characteristics. In this paper, the design load of DH gear pair is equal to $17500 \mathrm{Nm}$, and the theoretical contact ratio of DH gear pair is 3.42. Figure 19 shows the waveform change of SLTE under multiple loads for DH gear pair before and after modification. SLTE is illustrated three times by shifting the angular pitch. The rightmost column of Figures 19(a) and 19(b) shows the amplitude of SLTE of DH gear pair.

Figure 19(a) shows the case of the DH gear before modification. For DH gear with a standard tooth surface, the TE is approximately zero. In the process from entering meshing to exiting meshing, the meshing of quadruple tooth pairs and the meshing of triple tooth pairs alternately change. The SLTE of triple tooth pairs region is greater than that of quadruple tooth pairs. Because there is no STE to compensate for the difference of SLTE in different meshing zones, as the load increases, the change of the SLTE waveform gradually increases. In other words, the amplitude of SLTE increases linearly with the increase of the load, as shown by the black curve in Figure 19(c).

Figure 19(b) shows the case of DH gear after topological modification. When load is increased from the initial value of $1500 \mathrm{Nm}$ to the design load, the amplitude of SLTE increases first and then decreases. This is due to the reduction of the contact ratio of the gear pair caused by the modification. When the load is small, there is an alternation of triple tooth pairs meshing and double tooth pairs meshing in the process of the tooth from meshing-in to meshing-out. When the load exceeds the design load, the amplitude of SLTE continues to gradually increase. This is because with the increase of the load, the actual contact ratio of the gear 


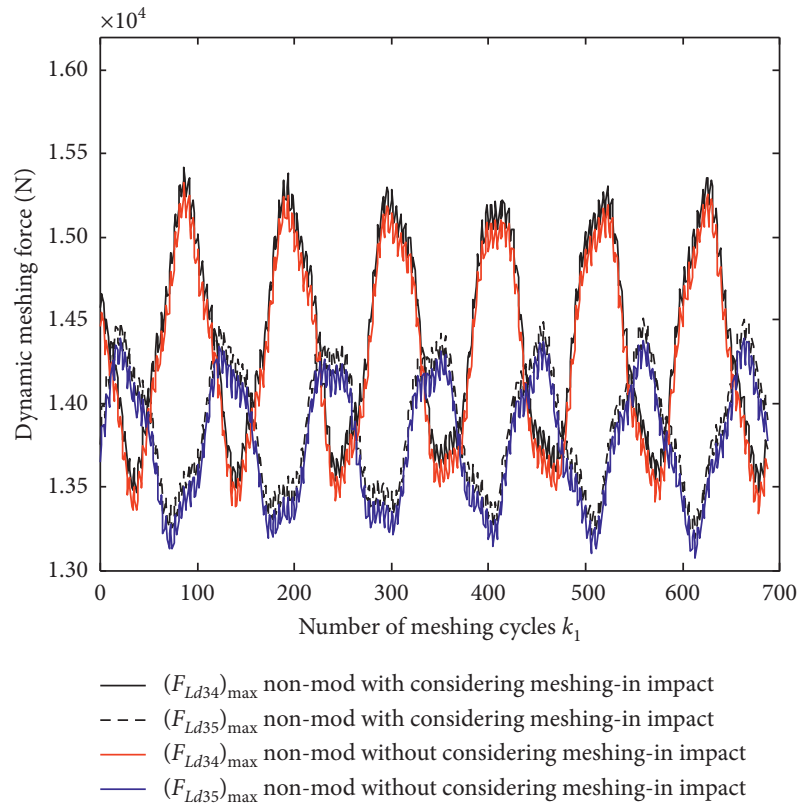

(a)

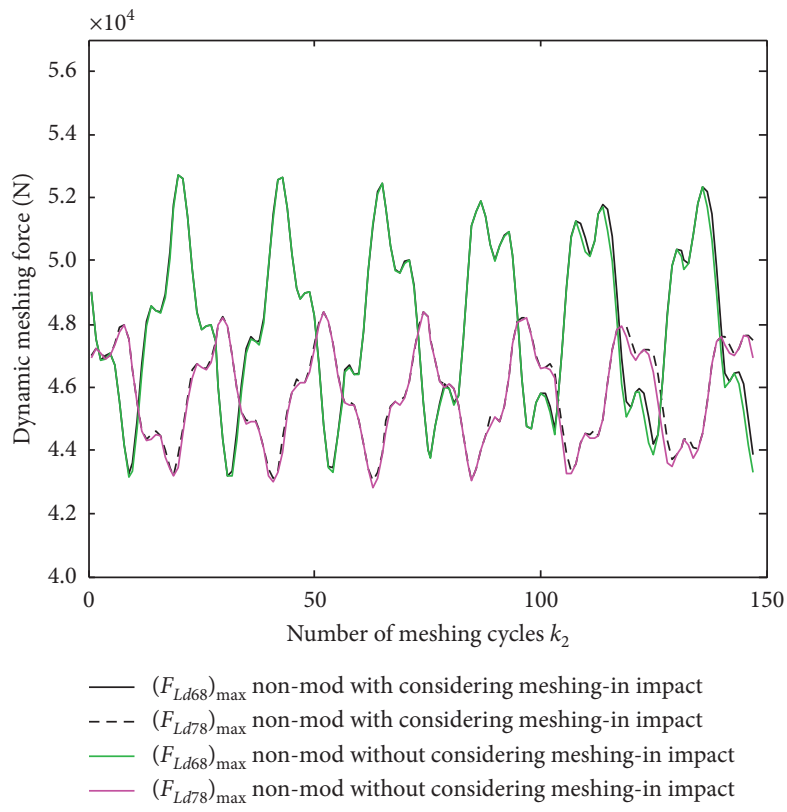

(b)

FIGURE 17: The maximum dynamic meshing force of gear pair with and without considering meshing-in impact: (a) second-stage spur gear pair; (b) third-stage DH gear pair.

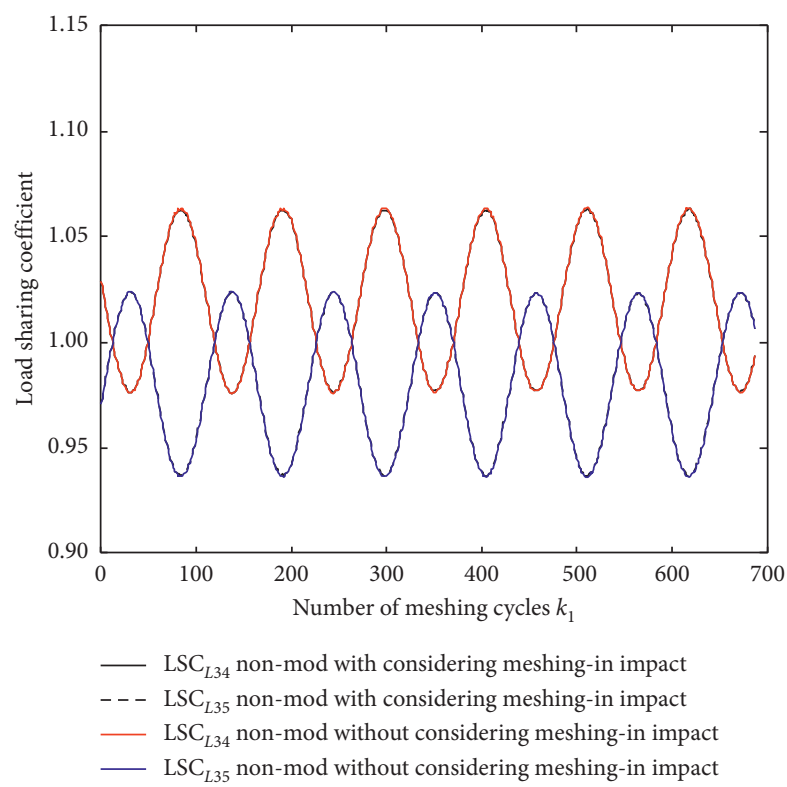

(a)

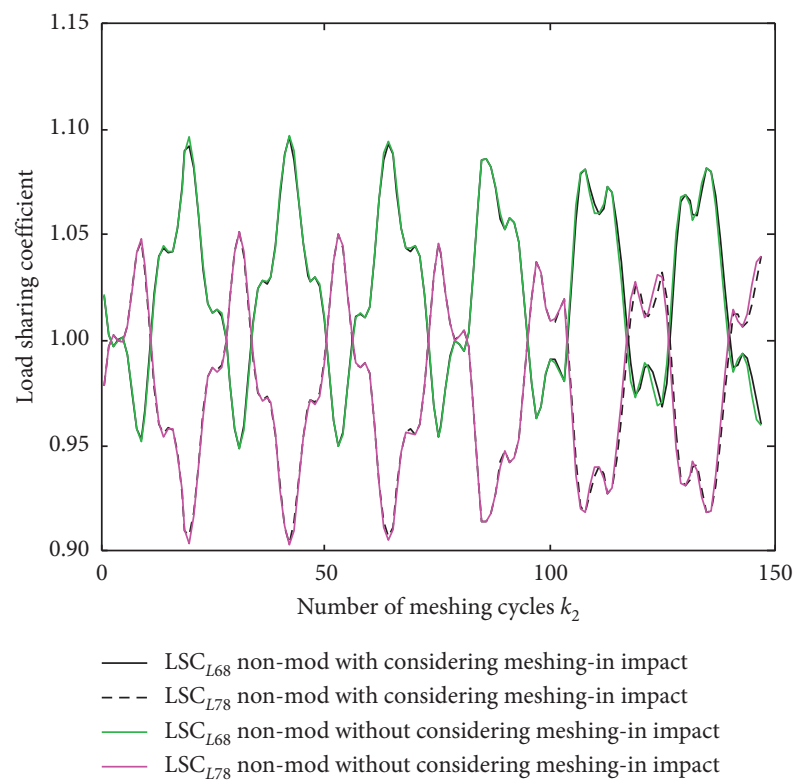

(b)

FIGURE 18: Instantaneous LSC of second and third stage with and without considering meshing-in impact: (a) instantaneous LSC for second-stage spur gear pair; (b) instantaneous LSC for third-stage DH gear pair.

pair gradually increases and finally reaches the theoretical contact ratio. In the process of tooth entering meshing to exiting meshing, the quadruple tooth pairs meshing and triple tooth pairs meshing alternate, which is the same as the meshing situation of the $\mathrm{DH}$ gear before modification. However, because the STE after modification compensates the difference of SLTE in different meshing areas, the amplitude of SLTE after modification is still much smaller than that before modification. Before and after modification, the amplitude of SLTE changes from $2.495^{\prime \prime}$ to $0.220^{\prime \prime}$, respectively; i.e., it decreased by $91.18 \%$, as shown in Figure 19(c).

The comprehensive meshing stiffness for $\mathrm{DH}$ gear pair under multiple loads before and after modification is shown 


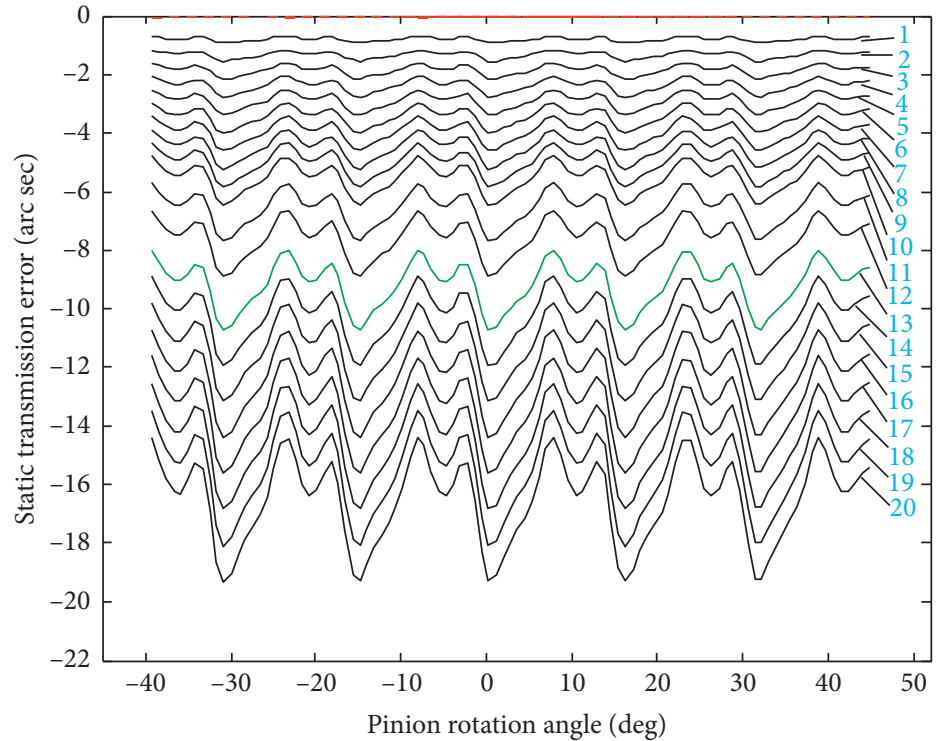

(a)

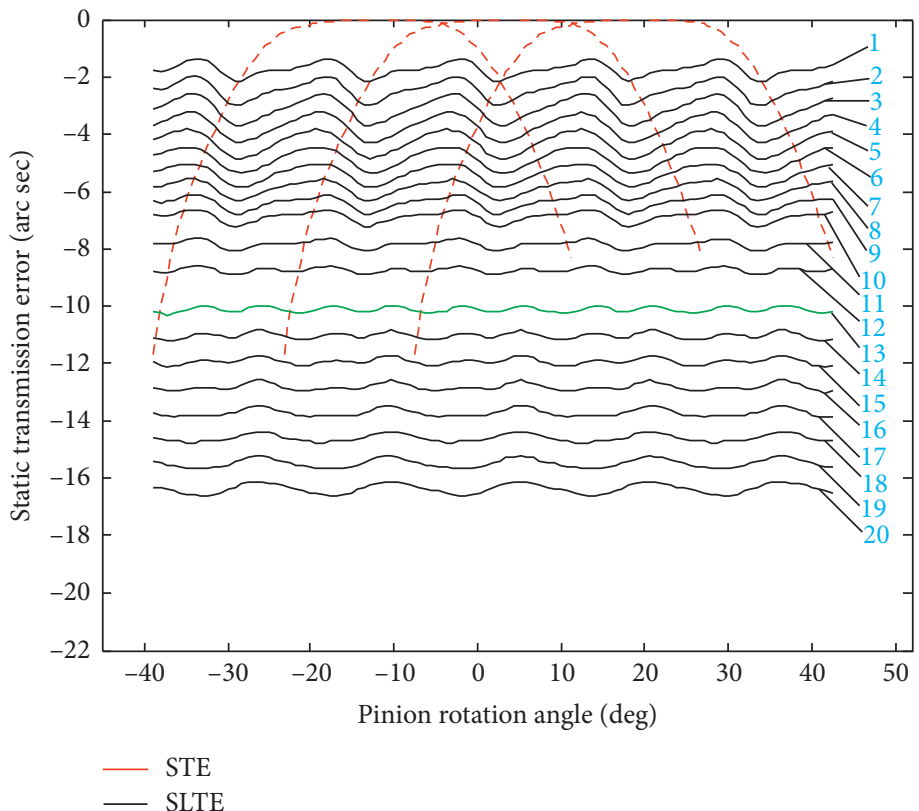

(b)
- STE

— SLTE

- SLTE
$1.1500 \mathrm{Nm}: 0.223$ $2.2500 \mathrm{Nm}: 0.365$ $3.3500 \mathrm{Nm}: 0.507$ $4.4500 \mathrm{Nm}: 0.649$ $5.5500 \mathrm{Nm}: 0.791$ $6.6500 \mathrm{Nm}: 0.933$

$7.7500 \mathrm{Nm}: 1.075$

$8.8500 \mathrm{Nm}: 1.217$

$9.9500 \mathrm{Nm}: 1.359$

$10.10500 \mathrm{Nm}: 1.501$

$11.12500 \mathrm{Nm}: 1.785$

$12.14500 \mathrm{Nm}: 2.069$

$13.17500 \mathrm{Nm}: 2.495$

$14.19500 \mathrm{Nm}: 2.782$

$15.21500 \mathrm{Nm}: 3.059$

$16.23500 \mathrm{Nm}: 3.350$

$17.25500 \mathrm{Nm}: 3.630$

$18.27500 \mathrm{Nm}: 3.910$

$19.29500 \mathrm{Nm}: 4.200$

$20.31500 \mathrm{Nm}: 4.480$
$1.1500 \mathrm{Nm}: 0.716$

$2.2500 \mathrm{Nm}: 0.893$

$3.3500 \mathrm{Nm}: 0.914$ $4.4500 \mathrm{Nm}: 0.917$

$5.5500 \mathrm{Nm}: 0.922$

$6.6500 \mathrm{Nm}: 0.827$

$7.7500 \mathrm{Nm}: 0.738$

$8.8500 \mathrm{Nm}: 0.634$

$9.9500 \mathrm{Nm}: 0.587$

$10.10500 \mathrm{Nm}: 0.520$

$11.12500 \mathrm{Nm}: 0.392$

$12.14500 \mathrm{Nm}: 0.310$

$13.17500 \mathrm{Nm}: 0.220$

$14.19500 \mathrm{Nm}: 0.290$

$15.21500 \mathrm{Nm}: 0.320$

$16.23500 \mathrm{Nm}: 0.350$

$17.25500 \mathrm{Nm}: 0.360$

$18.27500 \mathrm{Nm}: 0.370$

$19.29500 \mathrm{Nm}: 0.430$

20.31500Nm: 0.500

FIgURE 19: Continued. 


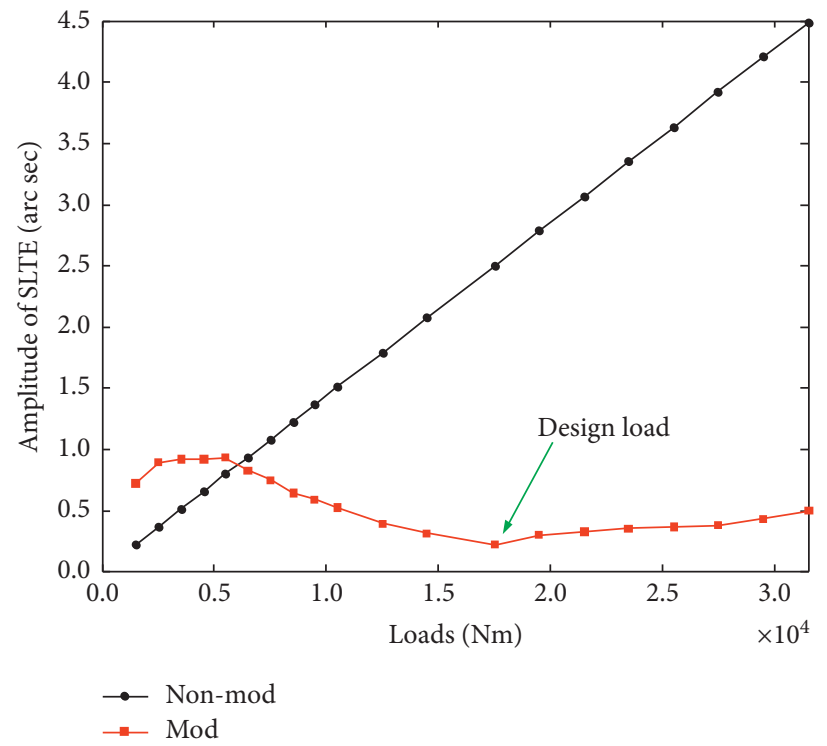

(c)

FIGURE 19: Waveform and variations of SLTE for DH gears before and after modification: (a) waveform of SLTE under multiple loads before modification; (b) waveform of SLTE under multiple loads after modification; (c) comparison of the amplitude of SLTE under multiple loads.

in Figure 20. Similarly, comprehensive meshing stiffness is illustrated three times by shifting the angular pitch. The rightmost column in Figures 20(a) and 20(b) indicates the average value of the meshing stiffness of $\mathrm{DH}$ gear pair.

Corresponding to Figures 19(a), and 20(a) represents the comprehensive meshing stiffness of the $\mathrm{DH}$ gear before modification. Since the DH gear has a standard involute tooth surface, the two tooth surfaces of the pinion and gear are completely conjugated under load. Furthermore, each meshing moment is characterized by a linear contact. Thus, with an increase in load, the average meshing stiffness increases slightly.

Corresponding to Figures 19(b), and 20(b) represents the comprehensive meshing stiffness of the $\mathrm{DH}$ gear after modification. The modification destroys the conjugate characteristics of the standard tooth surface, while pinion and gear tooth surface changes from a line contact to the point contact. The length of the contact line and the area of the contact ellipse of the modified tooth surface gradually increase with an increase in load. When load is increased from $1500 \mathrm{Nm}$ to the design load, the average meshing stiffness of the modified DH gear pair rapidly increases. When subjected to the design load, the average meshing stiffness decreases from $1.24269 \times 10^{9} \mathrm{~N} / \mathrm{m}$ before modification to $1.11100 \times 10^{9} \mathrm{~N} / \mathrm{m}$ after modification; i.e., it decreases by $10.60 \%$. When the applied load exceeds the design load, the actual contact ratio of the gear pair is close to the theoretical contact ratio. The average meshing stiffness slowly increases, and it approaches the average meshing stiffness before modification, as shown in Figure 20(c).

The research results in Figures 19 and 20 show that, on the one hand, modification reduces the amplitude of SLTE and the fluctuation amplitude of comprehensive meshing stiffness of the DH gear pair. On the other hand, modification leads to the decrease of the average meshing stiffness. The reduction of the fluctuation amplitude of comprehensive meshing stiffness is beneficial to the STTS's dynamic load characteristics, while the reduction of the average meshing stiffness will have an impact on the STTS's load sharing characteristics, which will be analyzed below.

The maximum meshing force in the tooth frequency cycle of second and third-stage gear pair of left-input twopath STTS before and after modification is shown in Figure 21. Only the fractional part of the dynamic load coefficient greater than 1 (indicating vibration) can be reduced via gear modification and dynamic design to improve the dynamic performance of gear transmission and reduce vibration level. Dynamic load factor of the STTS second-stage is reduced from 1.42443 before modification to 1.40194 after modification. Thus, dynamic load performance is improved by $5.30 \%$. However, third-stage dynamic load factor is significantly altered. The dynamic load factor is reduced from 1.20669 before modification to 1.13454 after modification, thereby increasing the dynamic load performance by $34.91 \%$. The above research shows that the modification has a good effect on improving the dynamic load characteristics of the STTS third stage.

The instantaneous LSC of the second-stage spur gear pair and third-stage DH gear pair before and after modification is shown in Figure 22. Only the fractional part of the LSC greater than 1 (indicating vibration) can be reduced to improve the load sharing performance of the gear transmission through modification. The LSC of the second-stage spur gear pair decreased from 1.06332 before modification to 1.06183 after modification, hence increasing the load sharing performance by $2.35 \%$. The LSC of the third-stage DH gear pair decreased from 1.09603 before modification to 1.09203 after 

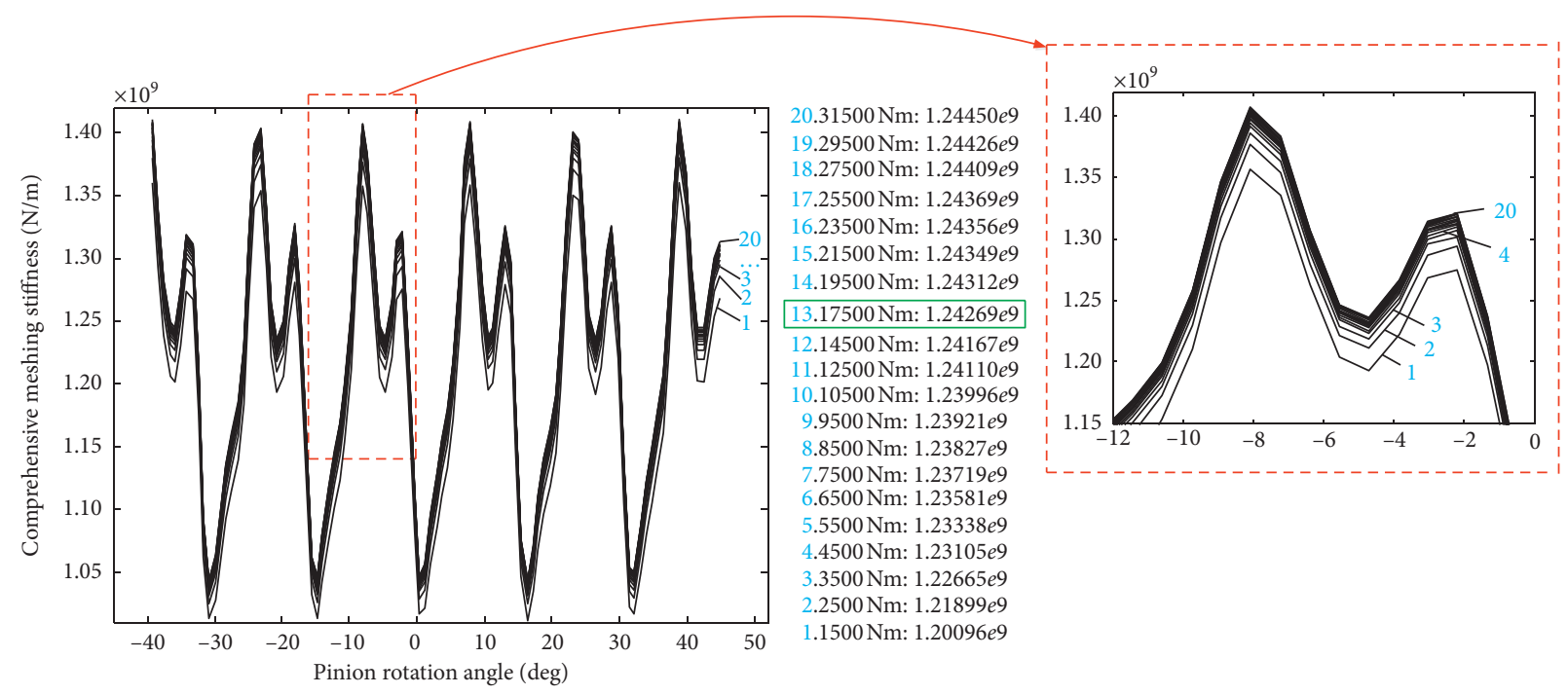

(a)

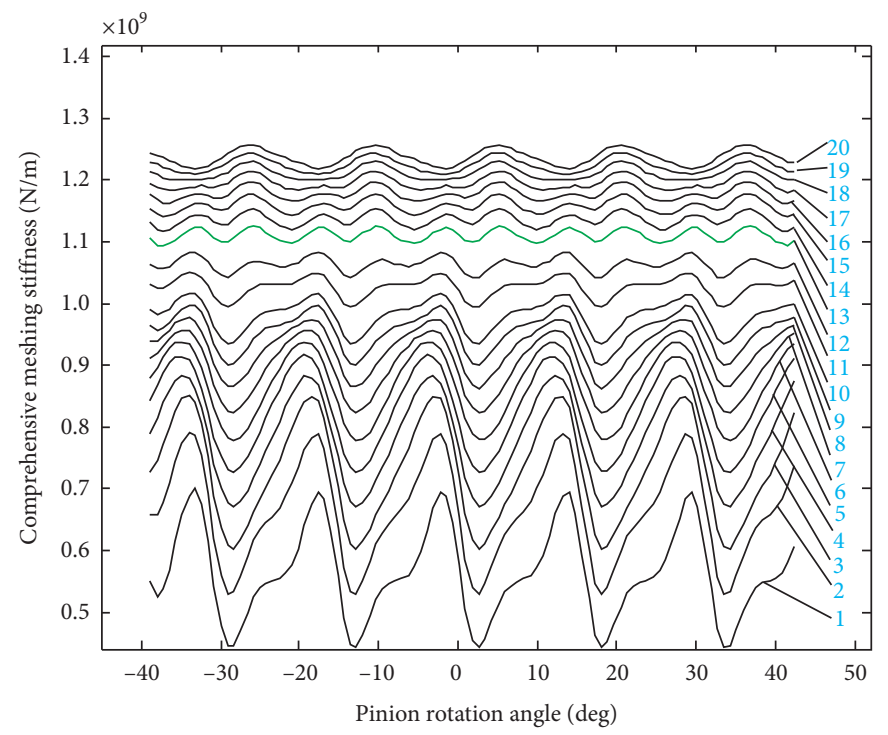

$20.31500 \mathrm{Nm}: 1.23788 e 9$

$19.29500 \mathrm{Nm}: 1.22528 e 9$

$18.27500 \mathrm{Nm}: 1.21136 e 9$

$17.25500 \mathrm{Nm}: 1.19590 \mathrm{e} 9$

$16.23500 \mathrm{Nm}: 1.17849 \mathrm{e} 9$

$15.21500 \mathrm{Nm}: 1.15875 e 9$

$14.19500 \mathrm{Nm}: 1.13624 e 9$

$13.17500 \mathrm{Nm}: 1.11100 e 9$

$12.14500 \mathrm{Nm}: 1.06445 e 9$

$11.12500 \mathrm{Nm}: 1.02693 \mathrm{e} 9$

$10.10500 \mathrm{Nm}$ : $0.98207 e 9$

$9.9500 \mathrm{Nm}: 0.95558 e 9$

$8.8500 \mathrm{Nm}: 0.92839 e 9$

$7.7500 \mathrm{Nm}: 0.89844 e 9$

$6.6500 \mathrm{Nm}$ : $0.86544 \mathrm{e} 9$

$5.5500 \mathrm{Nm}$ : $0.82785 e 9$

$4.4500 \mathrm{Nm}: 0.78278 e 9$

$3.3500 \mathrm{Nm}: 0.73004 e 9$

$2.2500 \mathrm{Nm}: 0.66282 e 9$

$1.1500 \mathrm{Nm}$ : 0.56231e9

(b)

Figure 20: Continued. 


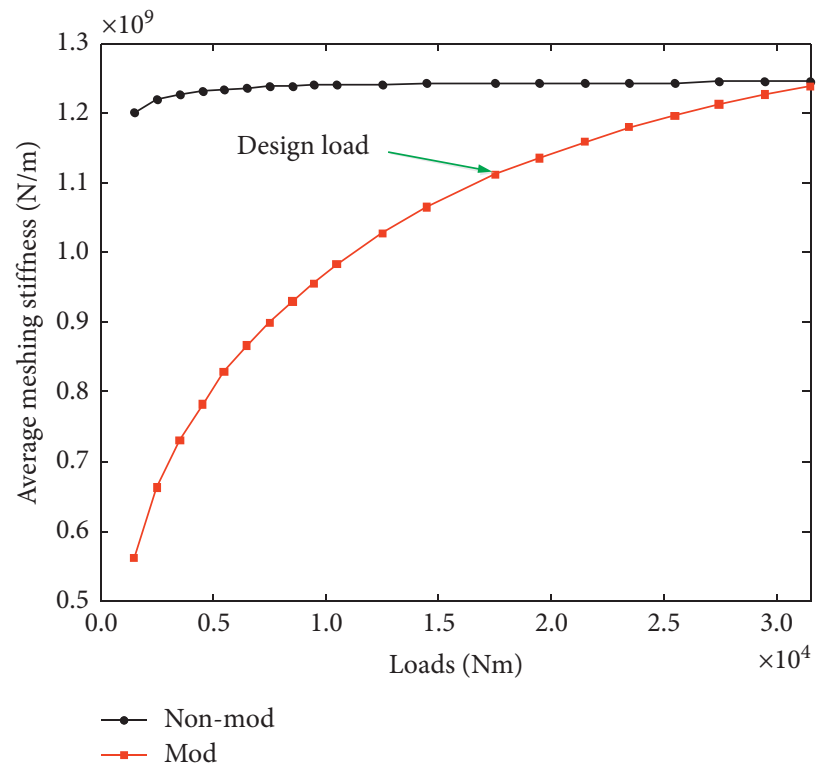

(c)

FIGURE 20: Comprehensive meshing stiffness for DH gear pair before and after modification: (a) comprehensive meshing stiffness under multiple loads before modification; (b) comprehensive meshing stiffness under multiple loads after modification; (c) comparison of average meshing stiffness under multiple loads before and after modification.

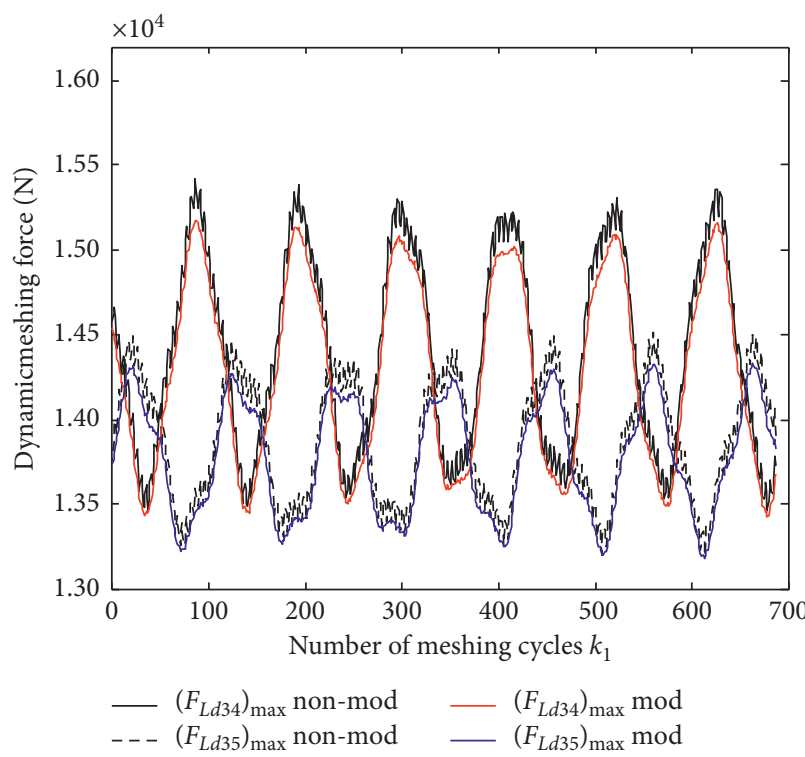

(a)

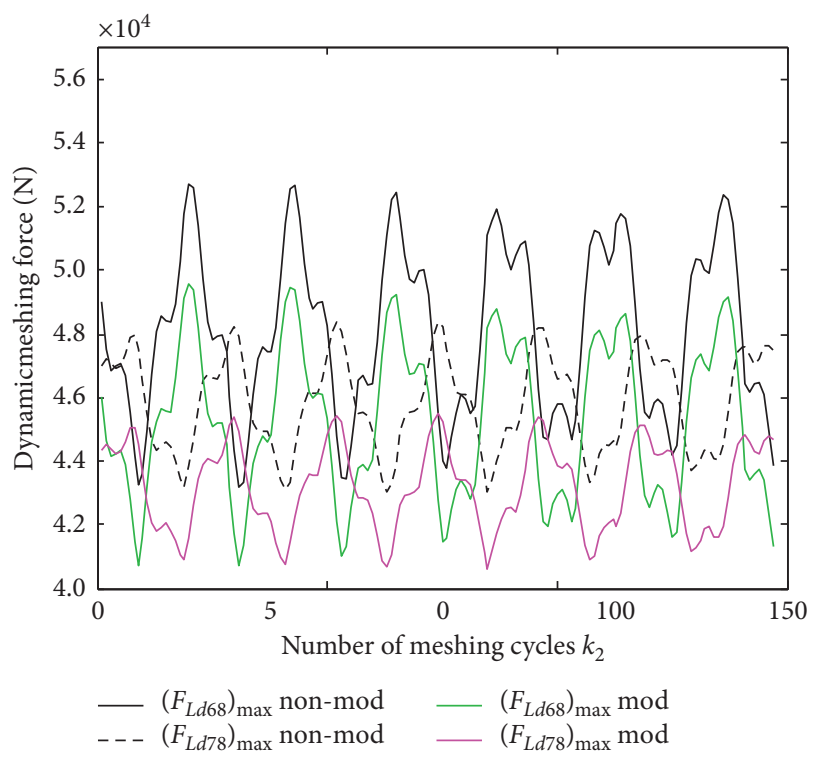

(b)

FIGURE 21: The maximum dynamic meshing force of gear pair before and after modification: (a) second-stage spur gear pair; (b) third-stage DH gear pair.

modification, therefore increasing the load sharing performance by $4.17 \%$. The LSC of the left-input twopath STTS depends on the LSC of the third stage. After modification, it is equal to $L S C_{L}=1.09203$. The results indicate that DH gear modification has a certain effect on improving the system's load sharing performance. 


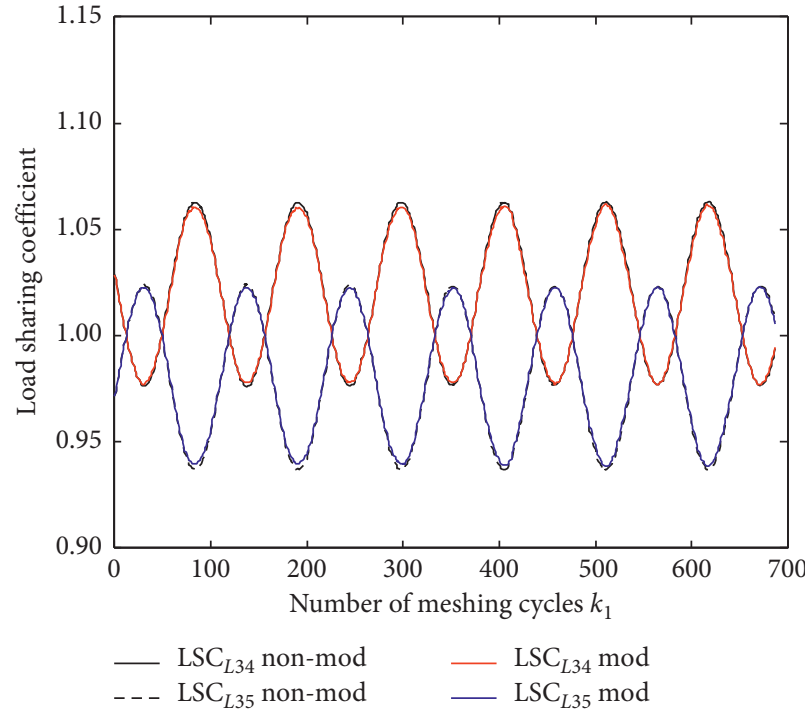

(a)

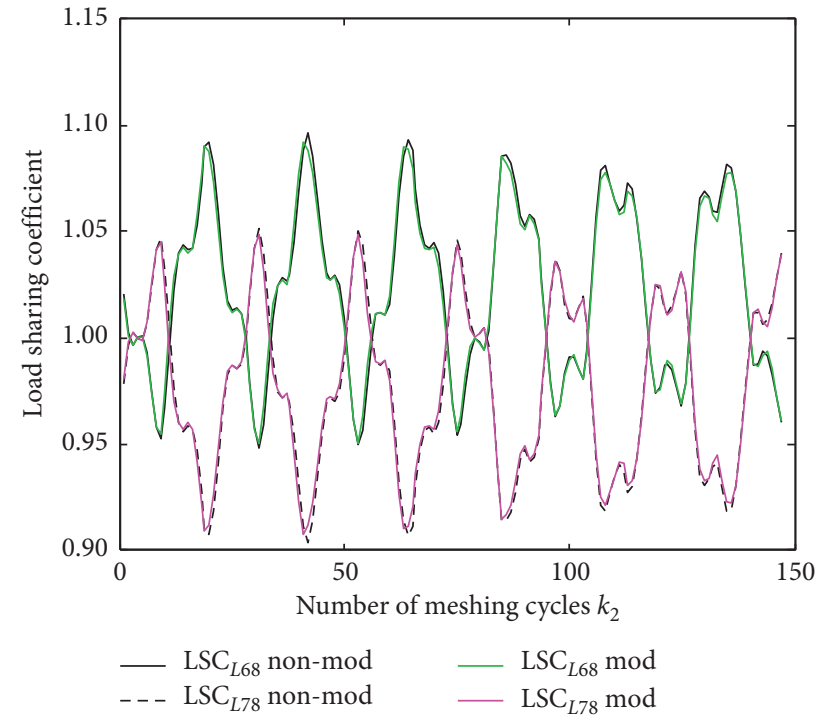

(b)

FIGURE 22: Instantaneous LSC of second and third stage before and after modification: (a) instantaneous LSC for second-stage spur gear pair; (b) instantaneous LSC for third-stage DH gear pair.

\section{Conclusions}

In this paper, the reversal method is used to calculate the meshing-in impact of standard involute spur gears and double-helical gears, and the meshing-in impact of spiral bevel gears and modified double-helical gears is accurately calculated based on tooth contact analysis and loaded tooth contact analysis. A dynamic model of two-input two-path split torque transmission system considering meshing error excitation, time-varying meshing stiffness excitation, and meshing-in impact excitation is proposed. Influence of double-helical gear modification on load sharing and dynamic load characteristics of two-input two-path split torque transmission system is investigated. The main conclusions are listed as follows:

(1) After considering the meshing-in impact, the dynamic meshing force of the gear pair increases, which is unfavorable to the transmission of the split torque transmission system. However, due to an increase in the average value of the maximum meshing force in each meshing period of the two paths, the load sharing coefficient of the system slightly decreases.

(2) After double-helical gear modification, the amplitude of static loaded transmission error, the fluctuation amplitude of comprehensive meshing stiffness, and the meshing-in impact are all reduced. Dynamic load characteristics of the third-stage gear pair are significantly improved, but dynamic load characteristics of the second-stage gear pair are less affected by double-helical gear modification.

(3) After double-helical gear modification, the average meshing stiffness is reduced. Simultaneously, due to an improvement of the split torque transmission system dynamic load characteristics, the load sharing

characteristics of the system are also improved to a certain extent.

\section{Abbreviations}

$$
\begin{aligned}
& z_{i j}(i=L, R, \\
& j=1 \ldots 7): \\
& z_{8}: \\
& \sigma_{1}, \sigma_{2}: \\
& \psi: \\
& \gamma:
\end{aligned}
$$

$\eta:$

$$
\begin{aligned}
& E_{L 3}, E_{L 4}: \\
& A_{L 3}, A_{L 4}: \\
& \lambda_{L 3}, \lambda_{L 4}, \mu_{L 3}, \mu_{L 4}: \\
& M L_{L 34}: \\
& e_{i 34}, e_{i 35}:
\end{aligned}
$$$$
e_{i 68}, e_{i 78}:
$$$$
\omega_{i 3}, \omega_{i 4}, \omega_{i 5}:
$$$$
\omega_{i 6}, \omega_{i 7}, \omega_{8}:
$$$$
\alpha_{t s}, \alpha_{t h}
$$

$P$ :
Gears

Center output double-helical gear System installation angle

System layout angle

The angle between the center line of each gear pair and positive $X$-axis direction

The angle between the meshing line of each gear pair and the positive direction of the $X$-axis

Eccentricity error of the spur pinion $z_{L 3}$ and the spur gear $z_{L 4}$ Installation error of the spur pinion $z_{L 3}$ and the spur gear $z_{L 4}$ Phase angle

The meshing line

Equivalent cumulative meshing error on the meshing line of spur gear pair 34 and 35

Equivalent cumulative meshing error on the meshing line of double-helical gear pair 68 and 78

Angular velocities of spur gear $z_{\mathrm{i} 3}, z_{\mathrm{i} 4}$, and $z_{\mathrm{i} 5}$

Angular velocities of double-helical gear $z_{\mathrm{i} 6}, z_{\mathrm{i} 7}$, and $z_{8}$ Transverse pressure angle of spur gear and double-helical gear

Total normal load 


\begin{tabular}{|c|c|}
\hline$Z:$ & Normal deformation \\
\hline$L_{\mathrm{TE}}:$ & Static loaded transmission error \\
\hline$A_{\mathrm{LTE}}:$ & $\begin{array}{l}\text { Amplitude of static loaded } \\
\text { transmission error }\end{array}$ \\
\hline$k:$ & Comprehensive meshing stiffness \\
\hline$\Delta \varphi_{k g}, \Delta \varphi_{k p}:$ & $\begin{array}{l}\text { Reverse angles of the driven gear and } \\
\text { driving pinion }\end{array}$ \\
\hline$r_{p}, r_{g}:$ & Pitch circle radii of pinion and gear \\
\hline$r_{b p}, r_{b g}:$ & Base circle radii of pinion and gear \\
\hline$r_{a g}:$ & Addendum circle radius of the gear \\
\hline$\Delta \varphi$ & Backward angle of the driven gear \\
\hline$v_{n p}, v_{n g}:$ & Normal velocities of pinion and gear \\
\hline$v_{s}:$ & Relative normal velocity \\
\hline$F_{s}:$ & Meshing-in impact \\
\hline$J_{p}, J_{g}:$ & $\begin{array}{l}\text { Moments of inertia for pinion and } \\
\text { gear }\end{array}$ \\
\hline$n:$ & Deformation coefficient \\
\hline$k_{\mathrm{s}}:$ & $\begin{array}{l}\text { Single meshing stiffness at the } \\
\text { engagement point }\end{array}$ \\
\hline$m_{i j}, I_{i j}:$ & Mass and moment of inertia of gear $z_{\mathrm{ij}}$ \\
\hline$m_{8}, I_{8}$ & $\begin{array}{l}\text { Mass and moment of inertia of the } \\
\text { central output gear } Z_{8}\end{array}$ \\
\hline$T_{L 1}, T_{R 1}:$ & Left- and right-input torques \\
\hline$T_{\text {out }}:$ & $\begin{array}{l}\text { Output torque on the central output } \\
\text { gear } Z_{8}\end{array}$ \\
\hline $\begin{array}{l}k_{i 12}, k_{\mathrm{i} 34}, k_{\mathrm{i} 35}, k_{\mathrm{i} 68} \\
k_{\mathrm{i} 78}:\end{array}$ & $\begin{array}{l}\text { Comprehensive meshing stiffness of } \\
\text { each gear pair }\end{array}$ \\
\hline$c_{i 12}, c_{\mathrm{i} 34}, c_{\mathrm{i} 35}, c_{\mathrm{i} 68}$ & Normal meshing damping of each \\
\hline$c_{\mathrm{i} 78}:$ & gear pair \\
\hline$k_{i t 23}, k_{i t 46}, k_{i t 57}$ & Torsional stiffness of dual-gear shaft \\
\hline$c_{i t 23}, c_{i t 46}, c_{i t 57}$ & Torsional damping of dual-gear shaft \\
\hline$\varphi_{i j}$ & $\begin{array}{l}\text { Torsional freedom of each gear about } \\
\text { their } Z \text {-axis }\end{array}$ \\
\hline$\varphi_{8}:$ & $\begin{array}{l}\text { Torsional freedom of central output } \\
\text { gear } Z_{8} \text { about its } Z \text {-axis }\end{array}$ \\
\hline$k_{i x 1}, k_{i x 2}, k_{i x 4}, k_{i x 5}$ & $\begin{array}{l}\text { Support stiffness of each gear in the } X \text { - } \\
\text { direction }\end{array}$ \\
\hline$c_{i x 1}, c_{i x 2}, c_{i x 4}, c_{i x 5}$ & $\begin{array}{l}\text { Support damping of each gear in the } \\
X \text {-direction }\end{array}$ \\
\hline$k_{i y 1}, k_{i y 2}, k_{i y 4}, k_{i y 5}:$ & $\begin{array}{l}\text { Support stiffness of each gear in the } Y \text { - } \\
\text { direction }\end{array}$ \\
\hline$c_{i y 1}, c_{i y 2}, c_{i y 4}, c_{i y 5}$ & $\begin{array}{l}\text { Support damping of each gear in the } \\
Y \text {-direction }\end{array}$ \\
\hline$p_{i 12}(t):$ & $\begin{array}{l}\text { Equivalent meshing line displacement } \\
\text { of spiral bevel gear pair }\end{array}$ \\
\hline$p_{i 34}(\mathrm{t}), p_{i 35}(\mathrm{t}):$ & $\begin{array}{l}\text { Equivalent meshing line displacement } \\
\text { of spur gear pair }\end{array}$ \\
\hline$p_{i 68}(\mathrm{t}), p_{i 78}(\mathrm{t}):$ & $\begin{array}{l}\text { Equivalent meshing line displacement } \\
\text { of double-helical gear pair }\end{array}$ \\
\hline$a_{i x}, a_{i y}, a_{i z}$ & $\begin{array}{l}\text { Spiral bevel gear calculation } \\
\text { coefficients }\end{array}$ \\
\hline $\begin{array}{l}F_{i n} 12, F_{i n} 34, F_{i n} 35 \\
F_{i n} 68, F_{i n} 78:\end{array}$ & Meshing force of each gear pair \\
\hline$F_{\text {is } 12}:$ & Meshing-in impact of spiral bevel gear \\
\hline$r_{i b 1}, r_{i b 2}:$ & $\begin{array}{l}\text { Equivalent pitch radii of spiral bevel } \\
\text { gear }\end{array}$ \\
\hline$r_{i b 3}, r_{i b 4}, r_{i b 5}:$ & $\begin{array}{l}\text { Base circle radii of second-stage spur } \\
\text { gear }\end{array}$ \\
\hline
\end{tabular}

$\begin{array}{ll}F_{i s 34}, F_{i s 35}: & \text { Meshing-in impact of spur gear pair } \\ r_{i b 6}, r_{i b 7}, r_{b 8}: & \text { Base circle radii of double-helical gear } \\ F_{i s 68}, F_{i s 78}: & \begin{array}{l}\text { Meshing-in impact of double-helical } \\ \text { gear pair }\end{array} \\ y_{1}, y_{2}, y_{3}, y_{4}, y_{5}, y_{6}: & \begin{array}{l}\text { Modification parameters } \\ s_{1}, s_{2}, s_{3}, s_{4}:\end{array} \\ & \begin{array}{l}\text { Location coordinates of the } \\ \text { modification points }\end{array} \\ C_{a}, C_{q}: & \text { Modification values } \\ u_{1}, l_{1}: & \text { Tooth surface parameters } \\ r_{1}\left(u_{1}, l_{1}\right), n_{1}\left(u_{1}, l_{1}\right): & \begin{array}{l}\text { Position and normal vectors of the } \\ \text { double-helical pinion theoretical }\end{array} \\ & \text { tooth surface } \\ q_{\text {min }}, q_{\text {max }}: & \text { Lower and upper bound for } y_{1}, y_{2}, \text { and } \\ & y_{5} \\ h_{\text {min }}, h_{\text {max }}: & \text { Lower and upper bound for } y_{3} \text { and } y_{4} \\ l_{\text {min }}, l_{\text {max }}: & \text { Lower and upper bound for } y_{6} \\ \text { NSGA-II: } & \text { Nondominated sorting genetic } \\ \text { STTS: } & \text { algorithm-II } \\ \text { DH gear: } & \text { Split torque transmission system } \\ \text { TVMS: } & \text { Double-helical gear } \\ \text { TCA: } & \text { Time-varying meshing stiffness } \\ \text { LTCA: } & \text { Tooth contact analysis } \\ \text { STE: } & \text { Loaded tooth contact analysis } \\ \text { SLTE: } & \text { Static transmission error } \\ \text { LSC: } & \text { Static loaded transmission error } \\ \text { non-mod: } & \text { Load sharing coefficient } \\ \text { mod: } & \text { Nonmodification } \\ & \text { Modification. }\end{array}$

\section{Data Availability}

All the data supporting this paper are included within the article.

\section{Conflicts of Interest}

The authors declare that they have no conflicts of interest.

\section{Acknowledgments}

This study was financially supported by the National Natural Science Foundation of China (project no. 51675424).

\section{References}

[1] G. White, "Split torque helicopter transmissions with widely separated engines," Proceedings of the Institution of $\mathrm{Me}$ chanical Engineers- Journal of Aerospace Engineering, vol. 203, no. 17, pp. 53-65, 1989.

[2] G. White, "Design study of a split-torque helicopter transmission," Proceedings of the Institution of Mechanical Engineers-Part G: Journal of Aerospace Engineering, vol. 212, no. 2, pp. 117-123, 1998.

[3] J. G. Kish, Sikorsky Aircraft Advanced Rotorcraft Transmission (ART) Program-Final Report, NASA, Wasington, DC, USA, 1993.

[4] T. L. Krantz, A Method to Analyze and Optimize the Load Sharing of Split Path Transmissions, NASA, Wasington, DC, USA, 1996. 
[5] S. R. Abraham, A. Jose, L. L. Marcos, and C. R. Enrique, "Split torque gearboxes: requirements, performance and applications," Mechanical Engineering, vol. 4, no. 11, pp. 55-74, 2012.

[6] A. Kahraman, "Load sharing characteristics of planetary transmissions," Mechanism and Machine Theory, vol. 29, no. 8, pp. 1151-1165, 1994.

[7] A. Kahraman, "Natural modes of planetary gear trains," Journal of Sound and Vibration, vol. 173, no. 1, pp. 125-130, 1994.

[8] P. Sondkar and A. Kahraman, "A dynamic model of a doublehelical planetary gear set," Mechanism and Machine Theory, vol. 70, no. 6, pp. 157-174, 2013.

[9] C. Liu, D. Qin, T. C. Lim, and Y. Liao, "Dynamic characteristics of the herringbone planetary gear set during the variable speed process," Journal of Sound and Vibration, vol. 333, no. 24, pp. 6498-6515, 2014.

[10] M. Li, L. Xie, and L. Ding, "Load sharing analysis and reliability prediction for planetary gear train of helicopter," Mechanism and Machine Theory, vol. 115, pp. 97-113, 2017.

[11] F. Ren, D. Qin, T. C. Lim, and S. Lyu, "Study on dynamic characteristics and load sharing of a herringbone planetary gear with manufacturing errors," International Journal of Precision Engineering and Manufacturing, vol. 15, no. 9, pp. 1925-1934, 2014

[12] S. Mo, T. Zhang, G. Jin, Z. Feng, J. Gong, and S. Zhu, "Influence mechanism of multi-coupling error on the load sharing characteristics of herringbone gear planetary transmission system," Proceedings of the Institution of Mechanical Engineers-Part K: Journal of Multi-Body Dynamics, vol. 233, no. 4, pp. 792-816, 2019.

[13] S. Mo, T. Zhang, G. G. Jin, X. L. Cao, and H. J. Gao, “Analytical investigation on load sharing characteristics of herringbone planetary gear train with flexible support and floating sun gear," Mechanism and Machine Theory, vol. 144, Article ID 103670, 2020.

[14] S. Mo, Y. Zhang, Q. Wu, H. Houjoh, and S. Matsumura, "Research on natural characteristics of double-helical star gearing system for GTF aero-engine," Mechanism and Machine Theory, vol. 106, pp. 166-189, 2016.

[15] F. Wang, S. Wang, and F. Li, "Theoretical analysis of the vibration modes of the star herringbone gear transmission system," Proceedings of the Institution of Mechanical Engineers-Part K: Journal of Multi-Body Dynamics, vol. 234, no. 2, pp. 358-368, 2019.

[16] S. Y. Wang, R. P. Zhu, and J. Feng, "Study on load sharing behavior of coupling gear-rotor-bearing system of GTF aeroengine based on multi-support of rotors," Mechanism and Machine Theory, vol. 147, Article ID 103764, 2020.

[17] E. Bechhoefer, R. Li, and D. He, "Quantification of condition indicator performance on a split torque gearbox," Journal of Intelligent Manufacturing, vol. 23, no. 2, pp. 213-220, 2012.

[18] Y. F. Gui, R. P. Zhu, G. H. Jin, and Z. J. Li, "Dynamic and load sharing characteristics analysis of a nonlinear cylindrical gear split-torque transmission system with backlash," Journal of Vibration and Shock, vol. 33, no. 18, pp. 177-184+189, 2014.

[19] H. Dong, Y. Cao, and Z. Fang, "Dynamic vibration characteristic analysis for the power-split transmission system based on loaded tooth contact analysis," Shock and Vibration, vol. 2015, Article ID 871894, 15 pages, 2015.

[20] N. Zhao, W. Li, T. Hu, H. Guo, R. Zhou, and Y. Peng, "Quasistatic load sharing behaviours of concentric torquesplit face gear transmission with flexible face gear," Mathematical Problems in Engineering, vol. 2018, no. 7, 12 pages, Article ID 6568519, 2018.
[21] Z. H. Hu, J. Y. Tang, Q. S. Wang, S. Chen, and L. Qian, "Investigation of nonlinear dynamics and load sharing characteristics of a two-path split torque transmission system," Mechanism and Machine Theory, vol. 152, Article ID 103955, 2020.

[22] G. H. Jin, X. T. Xu, and R. P. Zhu, "Analysis of load sharing mechanism and parameter matching of gear split torque drive system," Journal of Aerospace Power, vol. 35, no. 11, pp. 2306-2315, 2020.

[23] S. Li, "Effects of machining errors, assembly errors and tooth modifications on loading capacity, load-sharing ratio and transmission error of a pair of spur gears," Mechanism and Machine Theory, vol. 42, no. 6, pp. 698-726, 2007.

[24] H. Han, Z. Zhao, H. Tian, H. Ma, Y. Yang, and X. Li, "Fault feature analysis of planetary gear set influenced by cracked gear tooth and pass effect of the planet gears," Engineering Failure Analysis, vol. 121, Article ID 105162, 2021.

[25] H. Ma, J. Zeng, R. Feng, X. Pang, and B. Wen, “An improved analytical method for mesh stiffness calculation of spur gears with tip relief," Mechanism and Machine Theory, vol. 98, pp. 64-80, 2016.

[26] Y. Huangfu, K. Chen, H. Ma, X. Li, H. Han, and Z. Zhao, "Meshing and dynamic characteristics analysis of spalled gear systems: a theoretical and experimental study," Mechanical Systems and Signal Processing, vol. 139, Article ID 106640, 2020.

[27] F. Guo and Z. D. Fang, "Experimental and theoretical study of gear dynamical transmission characteristic considering measured manufacturing errors," Shock and Vibration, vol. 2018, Article ID 9645453, 20 pages, 2018.

[28] C. J. Zhou, J. Y. Tang, and Z. H. Zhong, "Corner contact and impact friction of gear drive," Chinese Journal of Mechanical Engineering, vol. 44, no. 3, pp. 75-81, 2008.

[29] Y. Mu, Z. Fang, and W. Li, "Impact analysis and vibration reduction design of spiral bevel gears," Proceedings of the Institution of Mechanical Engineers-Part K: Journal of MultiBody Dynamics, vol. 233, no. 3, pp. 668-676, 2019.

[30] Y. Mu and X. He, "Design and dynamic performance analysis of high-contact-ratio spiral bevel gear based on the higherorder tooth surface modification," Mechanism and Machine Theory, vol. 161, Article ID 104312, 2021.

[31] Y. Zhang and Z. Fang, "Analysis of transmission errors under load of helical gears with modified tooth surfaces," Journal of Mechanical Design, vol. 119, no. 1, pp. 120-126, 1997.

[32] J. Jiang and Z. Fang, "Design and analysis of modified cylindrical gears with a higher-order transmission error," Mechanism and Machine Theory, vol. 88, pp. 141-152, 2015.

[33] Y. Mu, W. Li, Z. Fang, and X. Zhang, "A novel tooth surface modification method for spiral bevel gears with higher-order transmission error," Mechanism and Machine Theory, vol. 126, pp. 49-60, 2018.

[34] H. Ma, X. Pang, R. Feng, and B. Wen, "Evaluation of optimum profile modification curves of profile shifted spur gears based on vibration responses," Mechanical Systems and Signal Processing, vol. 70-71, pp. 1131-1149, 2016.

[35] Y. Mu and Z. Fang, "Design and analysis of high contact ratio spiral bevel gears by modified curvature motion method," Proceedings of the Institution of Mechanical Engineers-Part C: Journal of Mechanical Engineering Science, vol. 232, no. 19, pp. 3396-3409, 2018.

[36] F. Wang, J. Zhang, X. Xu, Y. Cai, Z. Zhou, and X. Sun, "New teeth surface and back (TSB) modification method for transient torsional vibration suppression of planetary gear 
powertrain for an electric vehicle," Mechanism and Machine Theory, vol. 140, pp. 520-537, 2019.

[37] C. Wang, "Study on 3-D modification for reducing vibration of helical gear based on TCA technology, LTCA technology and system dynamics," Mechanical Systems and Signal Processing, vol. 146, Article ID 106991, 2021.

[38] M. R. Kang and A. Kahraman, "An experimental and theoretical study of the dynamic behavior of double-helical gear sets," Journal of Sound and Vibration, vol. 350, pp. 11-29, 2015.

[39] C. Wang, H. Y. Cui, Q. P. Zhang, and W. M. Wang, "Modified optimization and experimental investigation of transmission error, vibration and noise for double helical gears," Journal of Vibration and Control, vol. 22, no. 1, pp. 108-120, 2016.

[40] M. R. Kang and A. Kahraman, "An experimental and theoretical study of quasi-static behavior of double-helical gear sets," Journal of Mechanical Design, vol. 143, no. 4, pp. 1-25, 2020.

[41] D. T. Qin and L. Y. Xie, Modern Handbook of Mechanical Design, Chemical Industry Press, Shanghai, China, 2019. 